DE93 012235

TO:

Division of Materials Sciences

Office of Basic Energy Sciences

Department of Energy

Washington, DC 20545

FROM :

Dr. Robert P. Wei

Department of Mechanical Engineering and Mechanics

Lehigh University

Bethlehem, PA 18015

REFERENCE: Grant No. DE-FG02-88ER45354, "Corrosion Fatigue of Iron-ChromiumNickel Alloys: Fracture Mechanics and Chemistry"

SUBJECT: Progress Report for Period 1 January to 30 November 1990

This progress report briefly summarizes the research performed under the referenced grant for the period from 1 January to 31 November 1990 , and contains a cumulative listing of technical presentations and publications dating back to 1 June 1988.

\title{
Technical Report of Progress
}

Under this grant, a multi-disciplinary research program is undertaken to address certain fundamental issues relating to corrosion fatigue crack growth in structurally important alloys in aqueous environments. The principal goal of the research is to develop and expand the scientific understanding of the processes that control corrosion fatigue crack growth, particularly for ferrous alloys in terms of the controlling mechanical and chemical/electrochemical processes and their interactions with the microstructure.

Focus is placed upon the austenitic iron-chromium-nickel (FeCrNi) alloys because of the need to resolve certain mechanistic issues and because of extensive utilization of these alloys in the power generation and chemical industries. Emphasis is given to the growth of short (small) cracks at low growth rates because crack growth in this regime is expected to be more sensitive to changes in external chemical/electrochemical variables. The slower growth rates would also facilitate critical testing of mechanistically based models in terms of their ability to predict long-term response from short-time data. The ongoing research utilizes a combined mechanics, materials science and chemistry/electrochemistry approach.

The program was initiated on 1 June 1988. Principal efforts during the past 11 months are as follows: (1) final resolution of fundamental issues relating to electrochemical techniques for measuring the kinetics of electrochemical reactions with bare steel surfaces; (2) determination of the kinetics of electrochemical reactions for the annealed Fe18Cr12Ni alloy in aqueous environments; (3) characterization of corrosion fatigue crack growth response for the annealed Fe18Cr12Ni alloy in aqueous environments; (4) studies of the microstructural aspects of fracture surfaces produced by aqueous corrosion fatigue in this alloy to provide information on the embrittlement mechanisms, 


\section{DISCLAIMER}

This report was prepared as an account of work sponsored by an agency of the United States Government. Neither the United States Government nor any agency thereof, nor any of their employees, makes any warranty, express or implied, or assumes any legal liability or responsibility for the accuracy, completeness, or usefulness of any information, apparatus, product, or process disclosed, or represents that its use would not infringe privately owned rights. Reference herein to any specific commercial product, process, or service by trade name, trademark, manufacturer, or otherwise does not necessarily constitute or imply its endorsement, recommendation, or favoring by the United States Government or any agency thereof. The views and opinions of authors expressed herein do not necessarily state or reflect those of the United States Government or any agency thereof. 
and preliminary examinations of the susceptibility of specific boundaries to hydrogen embrittlement, and (5) further development of techniques for preparing bicrystals of the Fel8Cr12Ni alloy. Progress in each of the areas is given in the following executive summary, and is then briefly described.

\section{Executive Summary} follows:

Principal findings from research conducted during this period are as

1. The fundamental question of "what is being measured in a scratched electrode test?" was unequivocally resolved. The scratched electrode test has been used to study the kinetics of reactions with bare metal surfaces for the past 10 years. Results from electrochemical experiments conducted during this period clearly show that the peak bare-surface current densities based on the scratched (and strained) electrode tests, as reported in previous studies, are seriously in error, and the rates of repassivation are grossly overestimated. The error in the magnitude of the current densities arose as a result of incorrect understanding of the nature and distribution of current between the bare and filmed portions of the specimen surface; with most of the initial current flowing as a double-layer charging current to the filmed portion of the surface. Overestimation of the repassivation rates is a consequence of this misunderstanding, and the very limited duration (much less than $100 \mathrm{~ms}$ ) of these experiments.

This finding has broad implication with respect to existing concepts of mechanisms for stress corrosion cracking and corrosion fatigue, corrosion, passivity, etc., many of which will need to be reexamined.

2. Influences of potential and $\mathrm{pH}$ on the reactions of bare surfaces are better understood. Results from this study showed the electrode potential of bare surfaces depended strongly on the solution $\mathrm{pH}$, being more cathodic at higher $\mathrm{pH}$. For the $\mathrm{Fe} 18 \mathrm{Cr} 12 \mathrm{Ni}$ alloy in deaerated $0.6 \mathrm{~N} \mathrm{NaCl}$ solution, at room temperature, the bare-surface electrode potential ranged from $-715 \mathrm{mV}$ SCE at $\mathrm{pH} 2$ to $-1057 \mathrm{mV} \mathrm{SCE}$ at $\mathrm{pH} 12$. The extent of reaction reflects the difference between this bare-surface potential and the applied potential; i.e., the state of the bare surface and that at the applied potential. The influence of potential at a given $\mathrm{pH}$ reflects the amount of charge needed to bring the bare surface to the state defined by the applied potential. Similarly, the influence of $\mathrm{pH}$ at a given applied potential reflects its influence on the bare surface potential, as well as the final state of the surface. The precise mechanisms for the reactions and the composition of the surfaces, however, still need to be determined.

3. Correlation between charge transfer and corrosion fatigue crack growth response has been established for this Fel8Cr12Ni alloy in deaerated $0.6 \mathrm{~N} \mathrm{NaCl}$ solution at room temperature. The correlation suggests that the electrochemical condition at the crack tip approximates that of free corrosion. Crack growth response was essentially independent of $\mathrm{pH}$, except that the rates are slower at $\mathrm{pH} 12$. The slower rates are tentatively attributed to the effect of surface film induced crack closure and the attendant reduction in the effective crack driving force. 
4. Strong correlation was established between the morphology of corrosion fatigue fracture surfaces and cracking in hydrogen charged samples (austenite grain boundary and twin boundary separation, and transgranular cracking along preferred planes within the austenite grains). This correlation provides further support for a hydrogen embrittlement mechanism for corrosion fatigue crack growth, and suggests the use of charging as an additional tool for studying the micromechanisms for crack growth.

The charging experiments also suggested the sensitivity of certain boundaries and specific crystallographic planes to hydrogen embrittlement, and provided evidence of austenite-to-martensite phase transformation. Effect of grain size was also suggested. These aspects require more detailed study and are being pursued.

5. Attempts at growing bicrystals by a strain annealing technique have not been successful. Although grain size of up to $8 \mathrm{~mm}$ has been achieved, the procedure is time-consuming and does not have the desired degree of consistency. A modification, using active straining during the annealing treatment, is being examined. Alternative approaches are being considered; one in which large grained specimens produced by this technique will be used, and the other, having bicrystals produced by a cooperating laboratory (such as, Sandia Livermore and HOWMET).

\section{Peak Bare-Surface Current Density Measurements}

Results from electrochemical experiments conducted during this period clearly show that the peak bare-surface current densities reported by previous investigators on the basis of scratched (and strained) electrode tests are seriously in error, and the rates of repassivation of stainless steels are grossly overestimated. The error in the magnitude of the current densities arose, apparently, as a result of incorrect understanding of how a potentiostat functions and of the nature and distribution of current between the bare and filmed portions of the specimen surfaces. Overestimation of the repassivation rates is a consequence of of this misunderstanding, and the very limited duration (much less than $100 \mathrm{~ms}$ ) of these experiments. The essential results are summarized in the following paragraphs. These results serve to remove much of the ambiguities regarding mechanisms for crack growth enhancement, and suggest that a careful reassessment of the conclusions, drawn on the basis of scratched electrode data, is needed.

As a part of the program to establish the relationship between electrochemical reactions with bare steel surfaces and corrosion fatigue crack growth response, an in situ fracture technique was developed for measuring the kinetics of reactions with bare surfaces [1]. These measurements [1,2] called into question the very high values of initial (peak) bare-surface current densities (on the order of 1 to $100 \mathrm{~A} / \mathrm{cm}^{2}$ ) obtained by the strained and scratched electrode techniques [3-5], and the method for their calculation. Wei et al. [2] suggested that these high values, most likely, had resulted from a failure to account for concomitant charging of the double-layer over the relatively large filmed (oxidized) portion of the specimens used in these techniques. Overestimation was exacerbated by placing the Luggin probe close to the scratch in the early experiments [3]. 
In a recent response, Kelly and Newman [6] sought to refute the assertion by Wei et al. [2] and to reaffirm the validity of the scratched electrode technique. They contended that the in situ fracture measurements of Wei et al. $[1,2]$ were in error, with the most likely sources being the low rate of data acquisition used ( 1 to $2 \mathrm{~ms}$ data interval) relative to the repassivation time, and the effect of ohmic potential drop. They supported their position with a series of scratched electrode experiments on a 304 stainless steel in deaerated $0.6 \mathrm{M} \mathrm{NaCl}$ solution, using essentially the same conditions utilized by Wei et al. [2]. By showing the peak bare-surface "current densities" (more appropriately, peak currents) to be essentially independent of the filmed-to-bare surface area ratio, they concluded that the scratched electrode technique indeed provided valid measurements of the rate of reactions with bare metal surfaces [6].

Unfortunately, these experiments were limited and failed to resolve the basic scientific issue of how much of the peak current in the scratched electrode experiment might be attributed to double layer charging as opposed to bare surface reactions. The underlying importance of this issue relates to the correct values for bare-surface dissolution current and repassivation time (or kinetics). For 304 stainless steel in deaerated $3.58 \mathrm{NaCl}$ solution at room temperature, the essential discrepancy involves an indicated initial current density of about $1 \mathrm{i} / \mathrm{cm}$ and a repassivation time of tens of milliseconds for the scratched electrode technique, versus tens of $\mathrm{mA} / \mathrm{cm}^{2}$ and seconds for the in situ fracture technique $[1,6]$.

To help resolve this fundamental issue, scratched electrode experiments were carried out in a manner similar to that describe in [6] to ensure a common basis for critical examination and discussion. The results affirmed the original assertions by Wei et al. [2], and showed that data acquisition rate was not responsible for the observed differences in current densities and repassivation rates. These results were described in the previous annual progress report, and are given in a separate paper [7] (see attachment). To bring a closure to this controversy, an in situ fracture experiment $[1,2]$ was designed to address the following basic question: Whether double-layer charging of the filmed surface is the main contributor to the measured peak current? This experiment was designed so that the current flow to the bare (fracture) surfaces and the filmed surface could be measured separately.

In this experiment, an extra rod with exposed surface (filmed surface) was connected in parallel to the working electrode (bare surface). The current to the bare surface was measured independently, with the aid of a zero resistance ammeter, along with the total current through the potentiostat [1]. From these measurements, the distribution of current between the bare and filmed surfaces could be determined. The in situ fracture experiment was conducted on the 304 stainless steel in deaerated $3.58 \mathrm{NaCl}$ solution, under potentiostatic control at $-400 \mathrm{mV} \mathrm{SCE}$, at room temperature. The ratio of filmed-to-bare surfaces was estimated to be $25: 1$.

Figure 1 shows the current supplied by the potentiostat (total current), and to the bare (fracture) surfaces as functions of time following specimen fracture. To better understand the distribution of currents, the first $30 \mathrm{~ms}$ of these currents are shown in linear coordinates in Fig. 2, along with the current to the filmed surface; the latter being the difference of the first two currents. It should be noted that the reaction rates indicated by the in 
situ experiments are consistent with that observed for the repassivation of an isolated bare surface and for galvanic coupling experiments $[1,2]$ (see also following subsection on bare surface reactions).

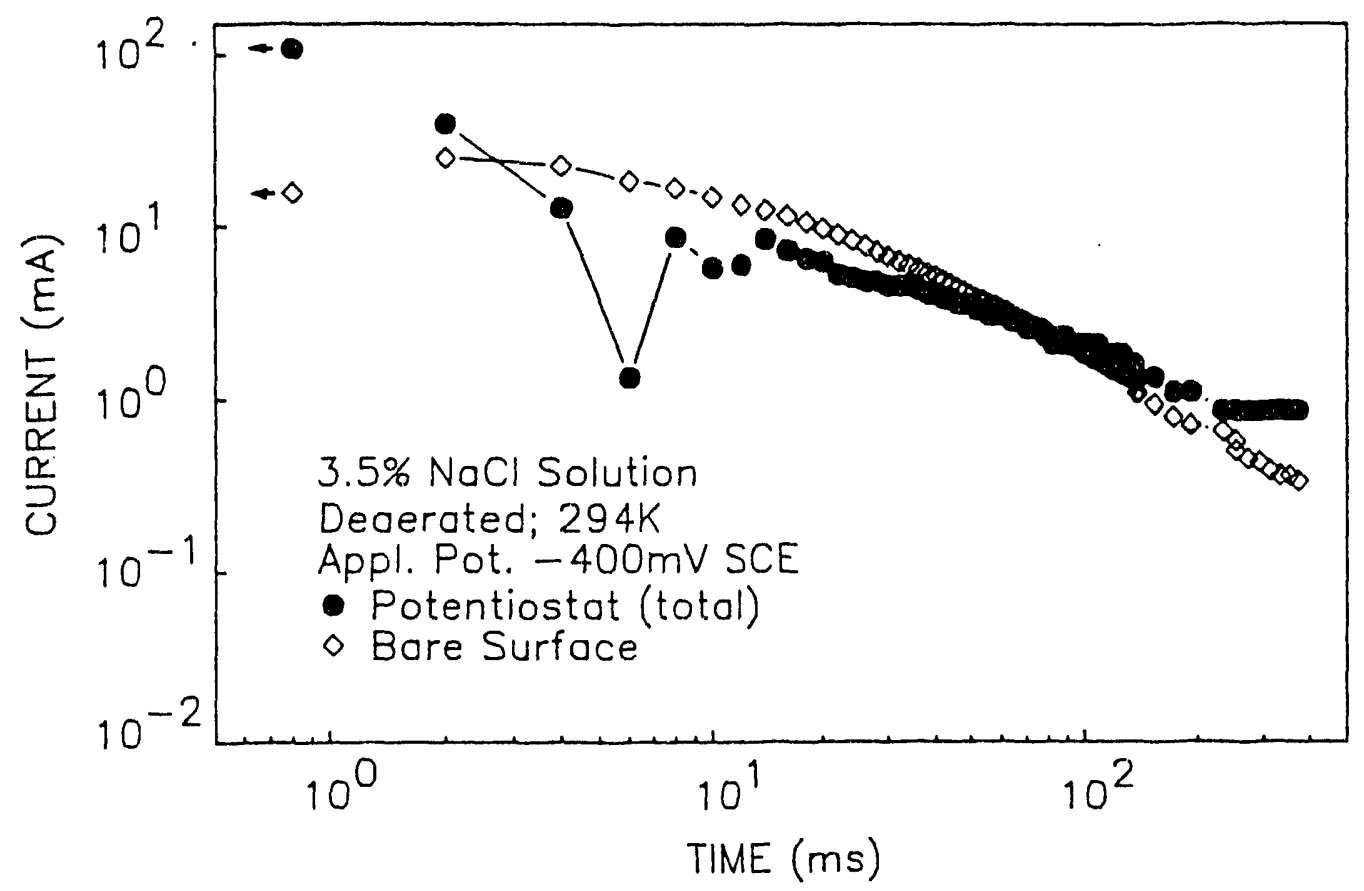

Fig. 1: Comparison of current supply by the potentiostat (total current) and that to the working electrode (bare surface) in an in situ fracture experiment.

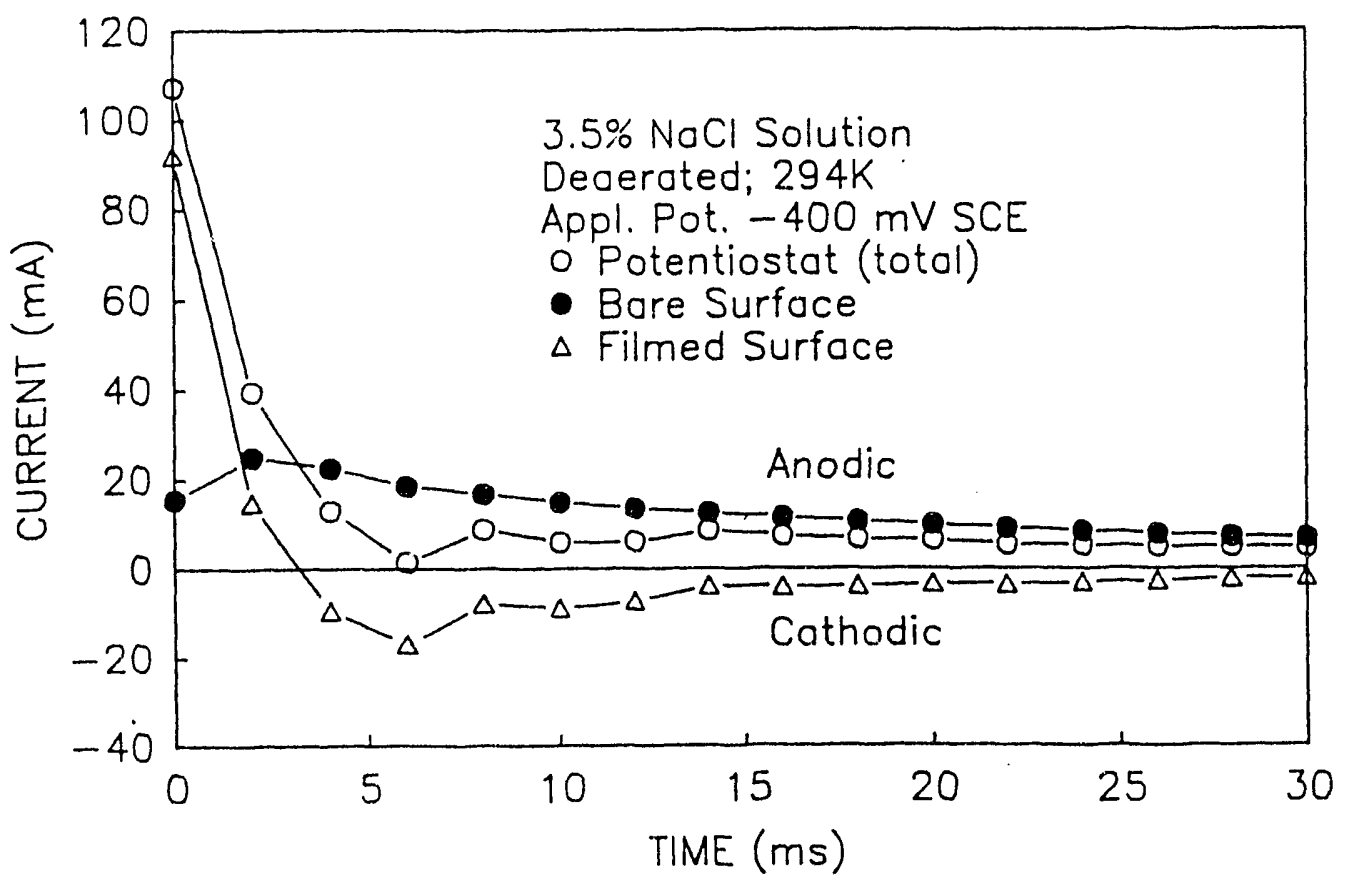

Fig. 2: Current flow from the potentiostat (total current) and to the bare and film surfaces following fracture (see Fig: 1). 
From these figures, it is clear that the predominant partion of the initial (peak) current was associated with charging of the filmed surface ( 91 out of $107 \mathrm{~mA}$ ). The peak current of $107 \mathrm{~mA}$ is consistent with those ${ }_{2}$ reported in [2] for this system. With an estimated current density of $5 \mathrm{~mA} / \mathrm{cm}^{2}$ (100 $\mathrm{mA}$ over $20 \mathrm{~cm}_{2}^{2}$ ) and charging time-constant of $1.2 \mathrm{~ms}$, the estimate charge density of $6 \mu \mathrm{C} / \mathrm{cm}^{2}$ is consistent with double layer charging. Following the initial charging transient, repassivation of the bare surfaces was supported by current from both the potentiostat and the filmed surface, and final equilibration was supported by current from the potentiostat to both surfaces (see Fig. 1). The time required to repassivate the freshly exposed surfaces is clearly well in excess of the $10 \mathrm{~ms}$ used in the Kelly and Newman experiments.

This finding shows that the procedure used in [3-6] for deducing baresurface reaction current densities from the scratched electrode tests is clearly in error, and cannot be supported by the evidence and rationale advanced by Kelly and Newman in [6]. Because of the presence of the filmed surface, the current transients produced in the scratched electrode tests are not true measures of the kinetics of bare-surface reactions. The bare-surface reaction current densities and repassivation kinetics in the literature, based on scratched electrode measurements, are therefore significantly overstated and need to be reexamined.

A brief communication detailing the results has been submitted for publication in the Journal of the Electrochemical Society, and a preprint copy is appended to this progress report.

\section{Electrochemical Reactions with Bare Surfaces}

Measurements of the kinetics of electrochemical reactions with bare surfaces of the $\mathrm{Fe} 18 \mathrm{Cr} 12 \mathrm{Ni}$ alloy were made, using the in situ fracture technique $[1,8]$. The influences of applied potential $(-400,-480$ and $-700 \mathrm{mV} \mathrm{SCE})$ and $\mathrm{pH}$ $(2,6.5$ and 12) were determined for the reactions in deaerated $0.6 \mathrm{~N} \mathrm{NaCl}$ solution at room temperature. In addition, repassivation of an isolated bare surface (produced by in situ fracture) was examined as a function of $\mathrm{pH}$ by following the change in electrode potential after specimen fracture. For the convenience of comparisons with corrosion fatigue crack growth data, the results are shown in terms of the amount of charge transferred (time integral of the reaction current transient) versus time in Figs 3 to 6 . Figures 3,4 and 5 show charge transferred as a function of applied potential at $\mathrm{pH}=2$, 6.5 and 12 , respectively. The data at an applied potential of $-480 \mathrm{mV}$ SCE are replotted and are shown as a function of $\mathrm{pH}$ in Fig. 6 . The potential versus time results from the isolated electrodes are shown in Fig. 7.

The charge transfer data may be qualitatively understood in relation to the electrode potential results shown in Fig. 7. The change in potential with time reflects the change in the state of the bare surface as it repassivates in the deaerated $0.6 \mathrm{~N} \mathrm{NaCl}$ solution; from its initially bare state towards its filmed state, reflected by the free corrosion potential. The results indicate that the electrode potential of the bare surface and the apparent free corrosion potential (as indicated by the electrode potential at $100 \mathrm{~s}$ ) are strongly dependent on the solution $\mathrm{pH}$. At a given applied potential, which is anodic with respect to the bare-surface potential, anodic reactions will proceed at the bare surface until the surface reaches a state that is consistent with the applied potential. This "passivation" or "filming" of the surface is reflected 


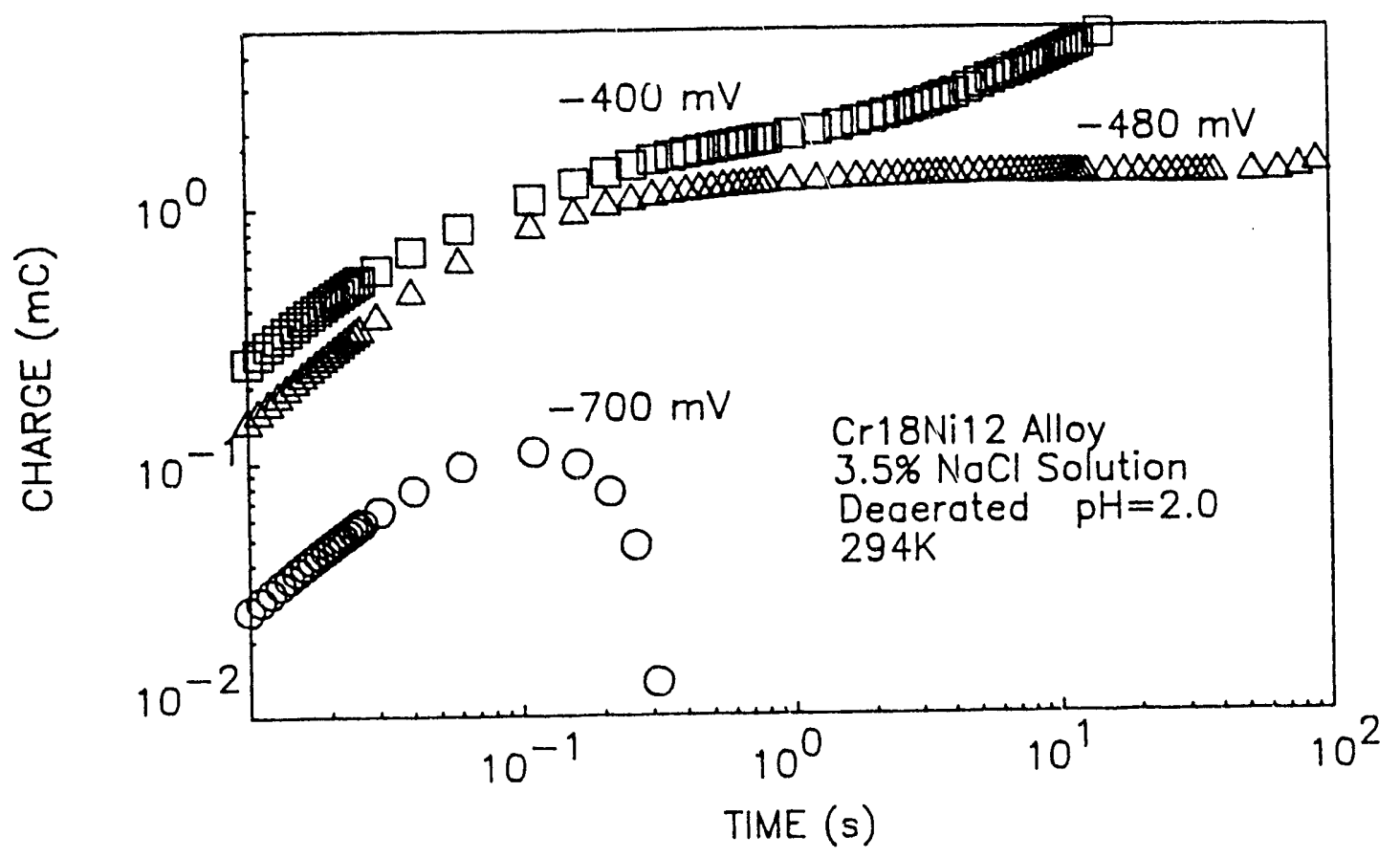

Fig. 3: Amount of charge transferred by the reactions of bare Fe18Cri2Ni alloy surfaces with deaerated $0.6 \mathrm{~N} \mathrm{NaCl}$ solution ( $\mathrm{pH}$ 2.0) at room temperature and different applied potentials.

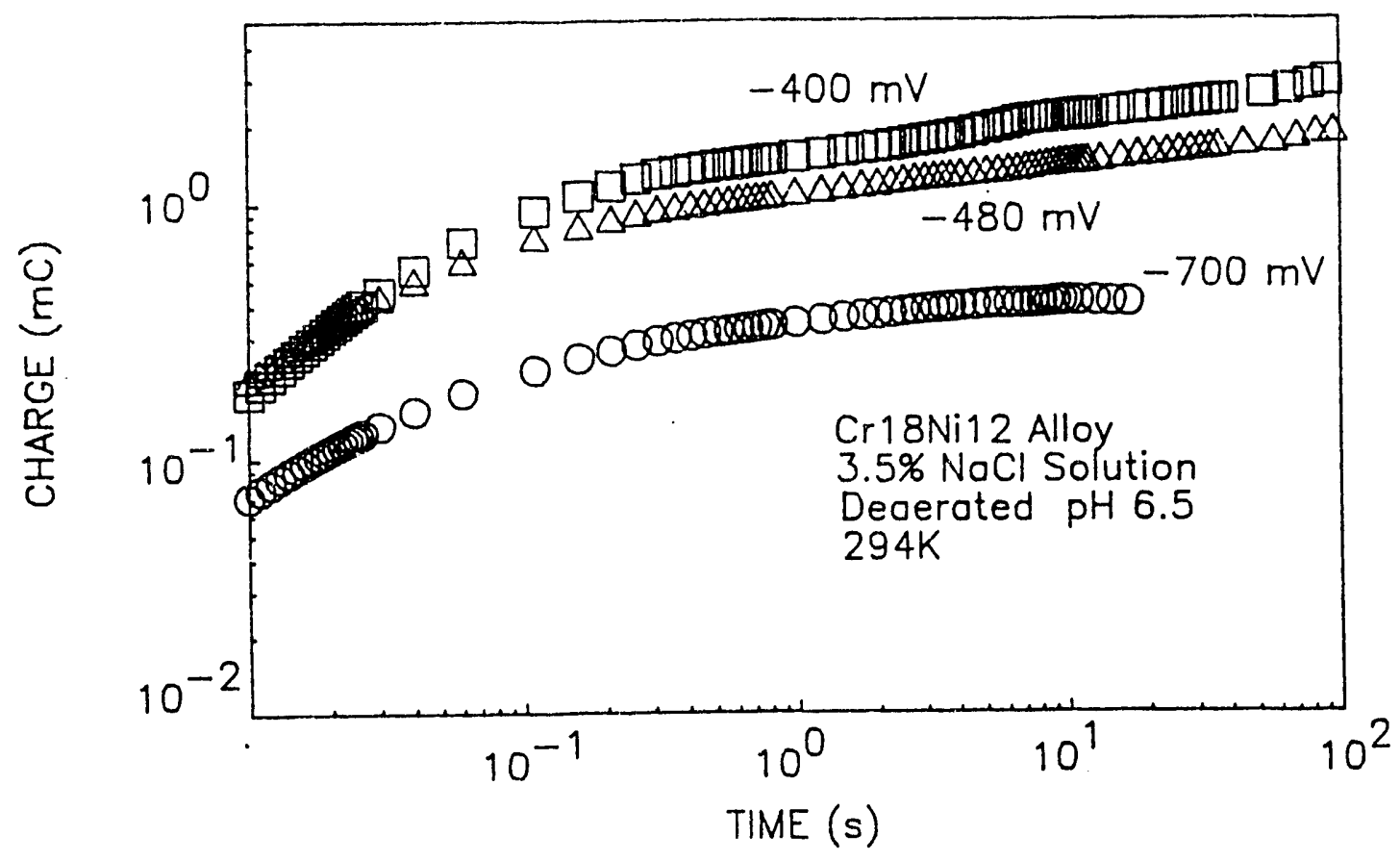

Fig. 4: Amount of charge transferred by the reactions of bare Fel8Cr12Ni alloy surfaces with deaerated $0.6 \mathrm{~N} \mathrm{NaCl}$ solution (pH $6.5)$ at room temperature and different applied potentials. 


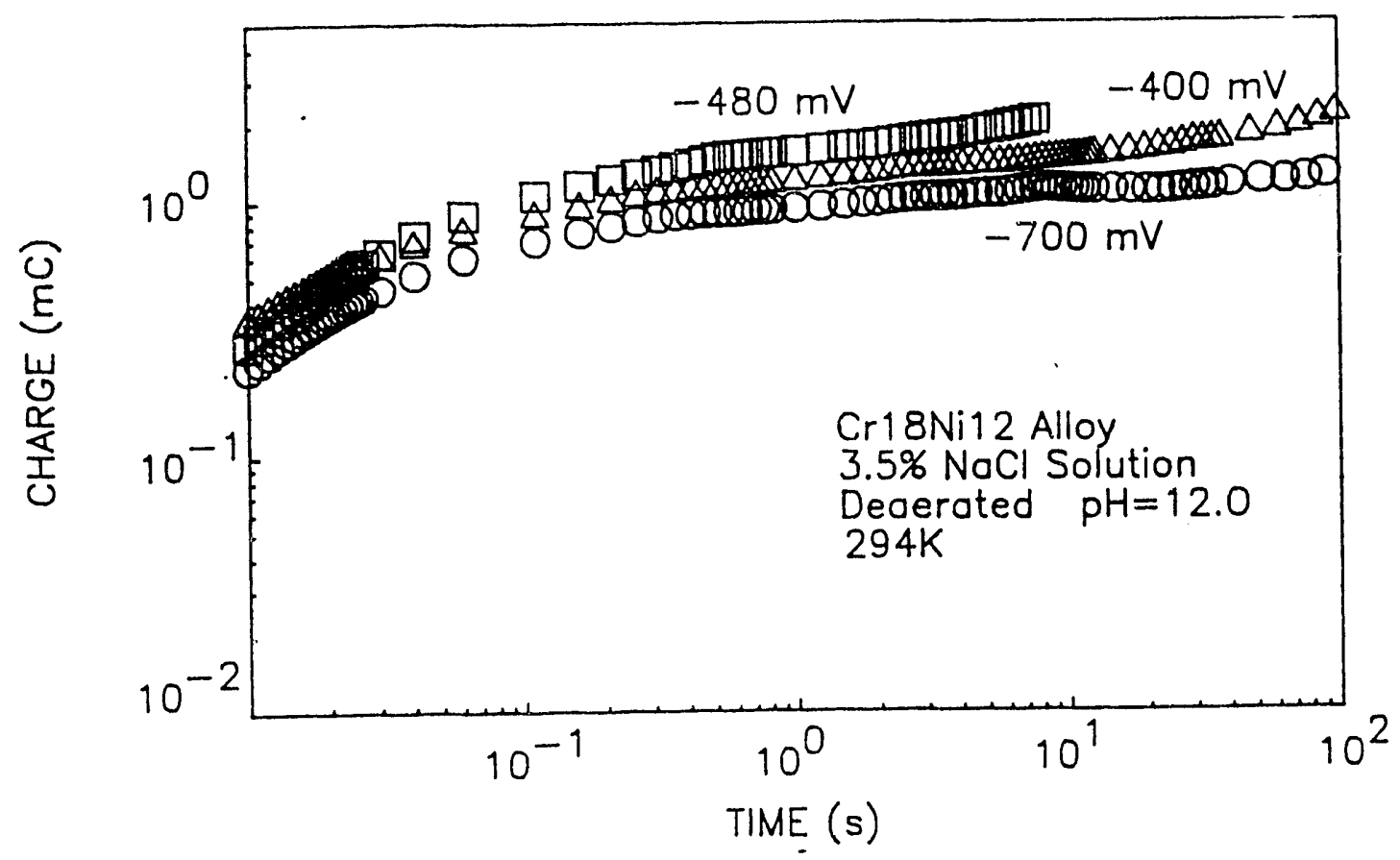

Fig. 5: Amount of charge transferred by the reactions of bare Fe18Cri2Ni alloy surfaces with deaerated $0.6 \mathrm{~N} \mathrm{NaCl}$ solution ( $\mathrm{pH}$ 12.0) at room temperature and different applied potentials.

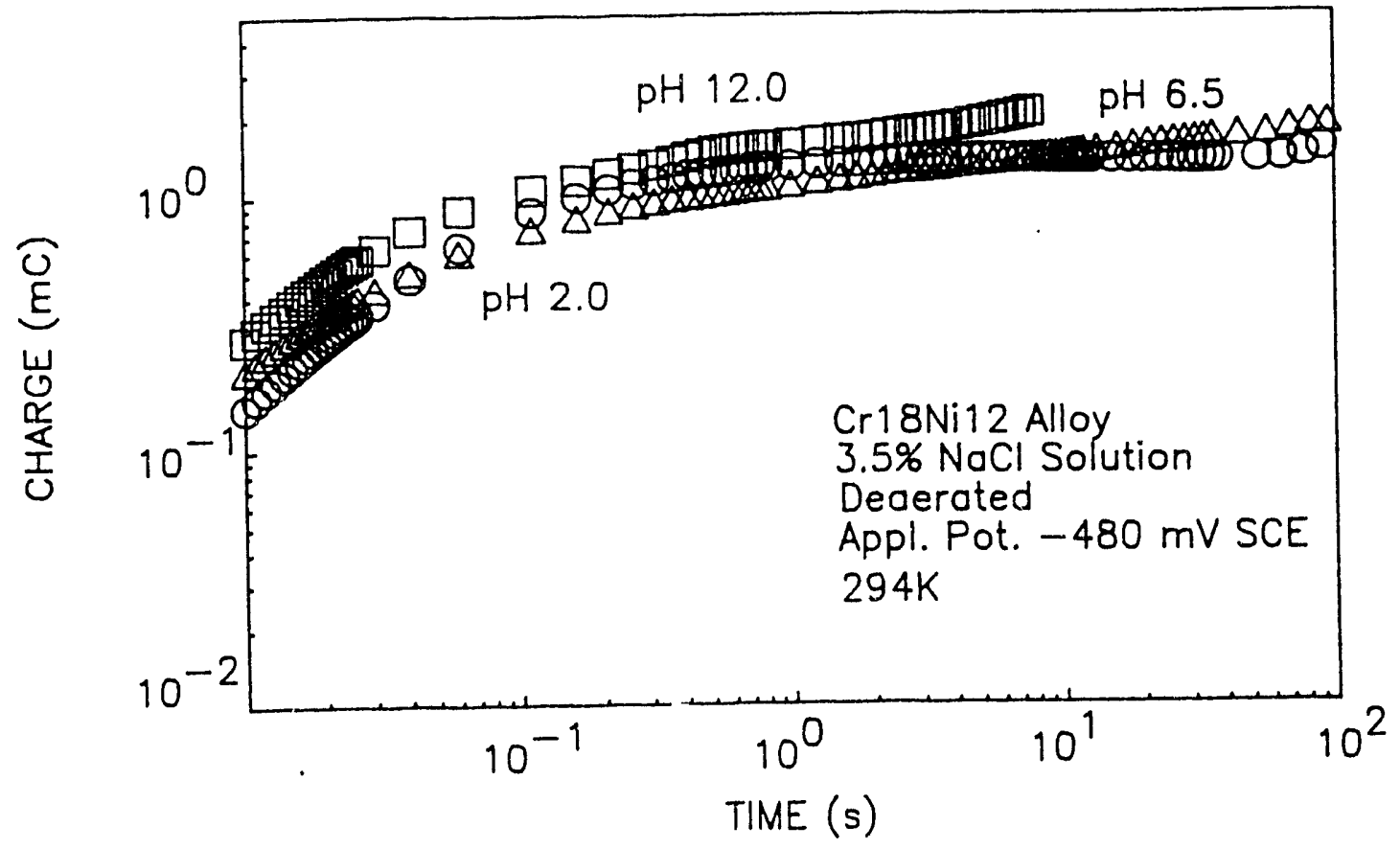

Fig. 6: Amount of charge transferred by the reactions of bare Fe18Cr12Ni allcy surfaces with deaerated $0.6 \mathrm{~N} \mathrm{NaCl}$ solution ( $\mathrm{pH}$ $2.0,6.5$ and 12.0 ) at room temperature and an applied potential of $-480 \mathrm{mV}$ SCE. 


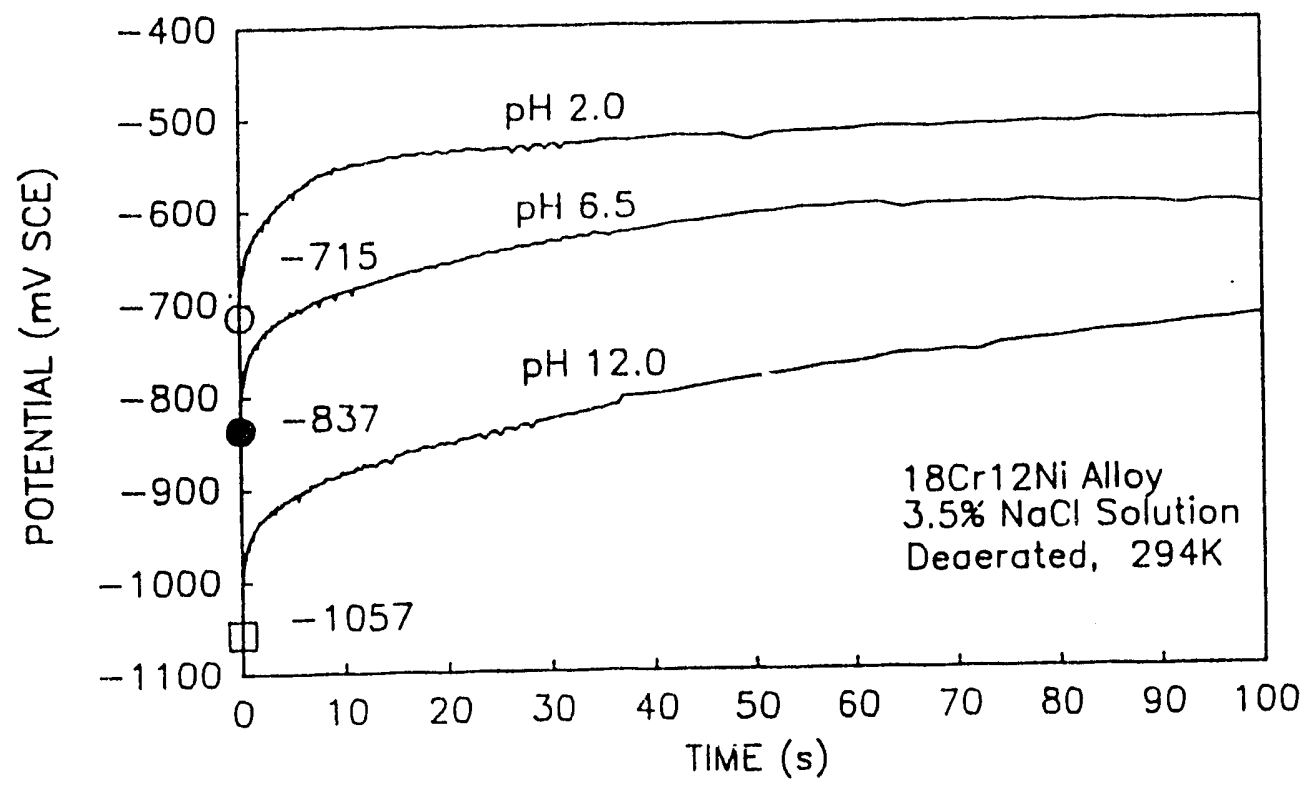

Fig. 7: Fquilibration of isolated bare Fe18Cr12Ni alloy surfaces in deaerated $0.6 \mathrm{~N} \mathrm{NaCl}$ solution ( $\mathrm{pH} 2.0,6.5$ and 12.0) at room temperature.

by the increasing amounts of charge transferred in Figs 3 to 6 . If the applied potential is anodic with respect to the free corrosion potential, then the residual current would be anodic and the surface film will continue to thicken. If it is more cathodic, on the other hand, a cathodic current will flow to maintain the surface at the state defined by the applied potential, which is reflected by the decrease in the amount of charge transferred shown by the data at $-700 \mathrm{mV}$ in Fig. 3 .

It is interesting to note that the reaction rates under externally imposed potentials (indicated by the charge transfer data) are consistent with the rate of equilibration of isolated electrodes, and that there is evidence for the formation of a surface film even in acidic chloride solutions. The results are consistent with previous findings on the 304 stainless steels (Fe18Cr8Ni alloy) and other high strength steels. Further studies are underway to investigate the influence of temperature and to understand the mechanisms for these reactions.

\section{Corrosion Fatigue Crack Growth and Electrochemical Reactions}

To examine the relationship between electrochemical reactions and corrosion fatigue, crack growth experiments were planned for the Fe18Cr12Ni alloy to investigate principally the influence of $\mathrm{pH}$ and temperature. Because of forced retirement of the DEC-based controllers for the testing machines and the need to switch vendors for the replacement equipment, these experiments were delayed. During this period, the influence of solution pH on crack growth has been determined.

The experiments were carried out under constant $\Delta K$ control, principally at $\Delta \mathrm{K}=15 \mathrm{MPa} / \mathrm{m}$, in a deaerated $0.6 \mathrm{~N} \mathrm{NaCl}$ solution at room temperature and an applied potential of $-700 \mathrm{mV} \mathrm{SCE}$. The experiments spanned frequencies from 
0.1 to $10 \mathrm{~Hz}$. The results are shown for $\mathrm{pH}$ values of $2.0,3.0,6.5$ and 12.0 in Figs 8 t.o 11. The growth rates and frequency dependence at the three lower $\mathrm{pH}$ values were essentially identical. The data at $\mathrm{pH} 12.0$ are 2 to 3 times slower, and the apparent frequency dependence is less strong.

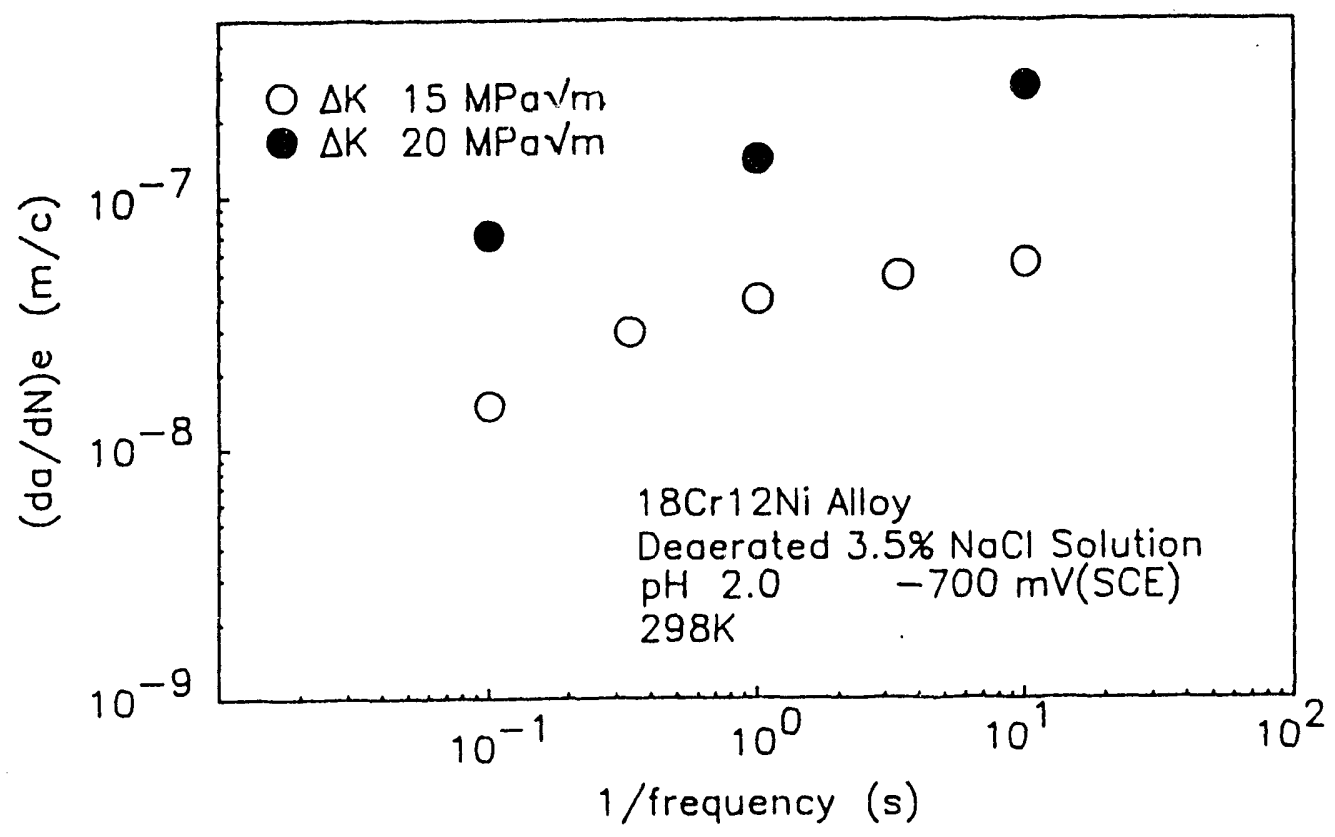

Fig. 8: Corrosion fatigue crack growth response of Fe18Cr12Ni alloy in deaerated $0.6 \mathrm{~N} \mathrm{NaCl}$ solution ( $\mathrm{pH} 2.0$ ) at room temperature and an externally applied potential of $-700 \mathrm{mV}$ SCE.

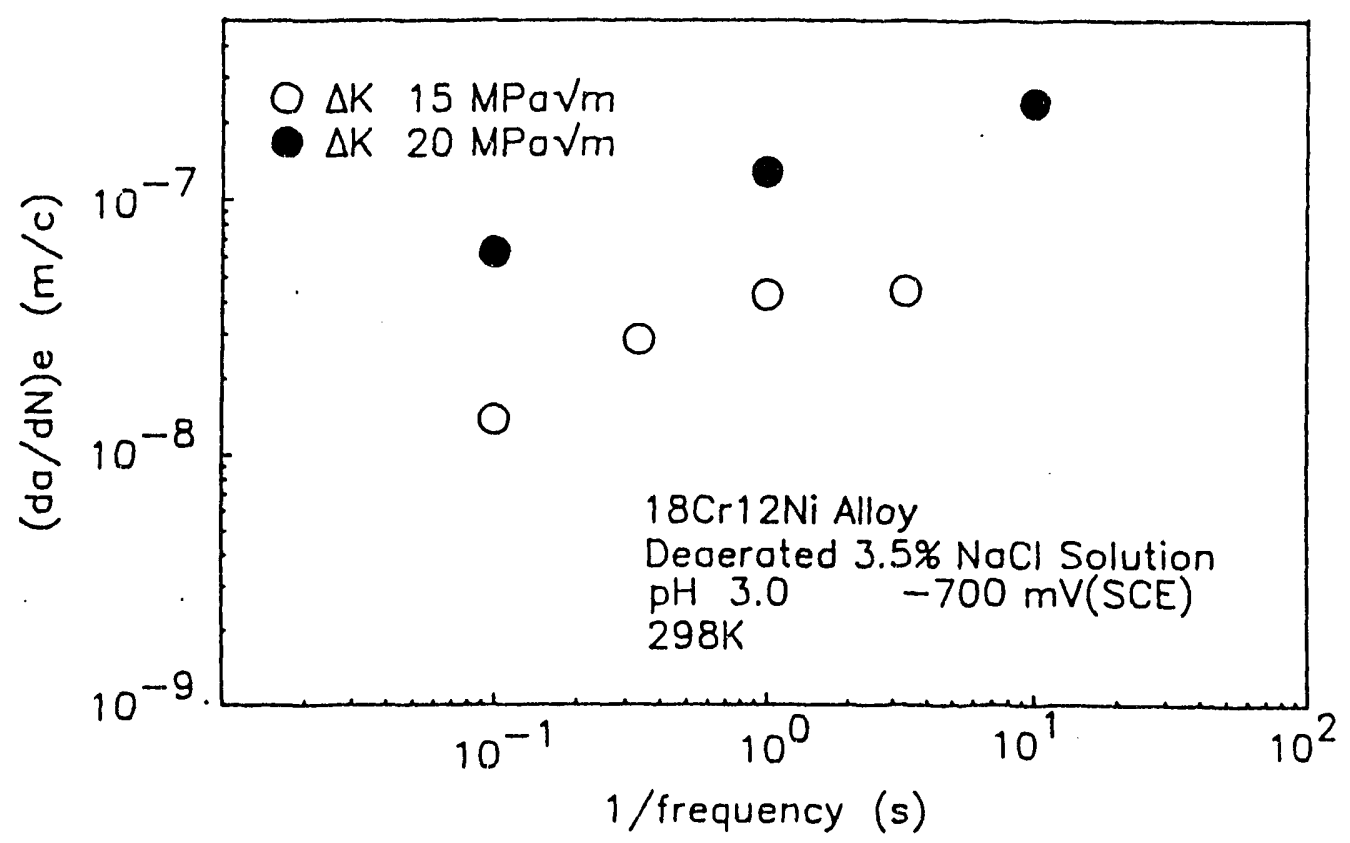

Fig. 9: Corrosion fatigue crack growth response of $\mathrm{Fe} 18 \mathrm{Cr} 12 \mathrm{Ni}$ alloy in deaerated $0.6 \mathrm{~N} \mathrm{NaCl}$ solution ( $\mathrm{pH} 3.0$ ) at room temperature and an externally applied potential of $-700 \mathrm{mV}$ SCE. 


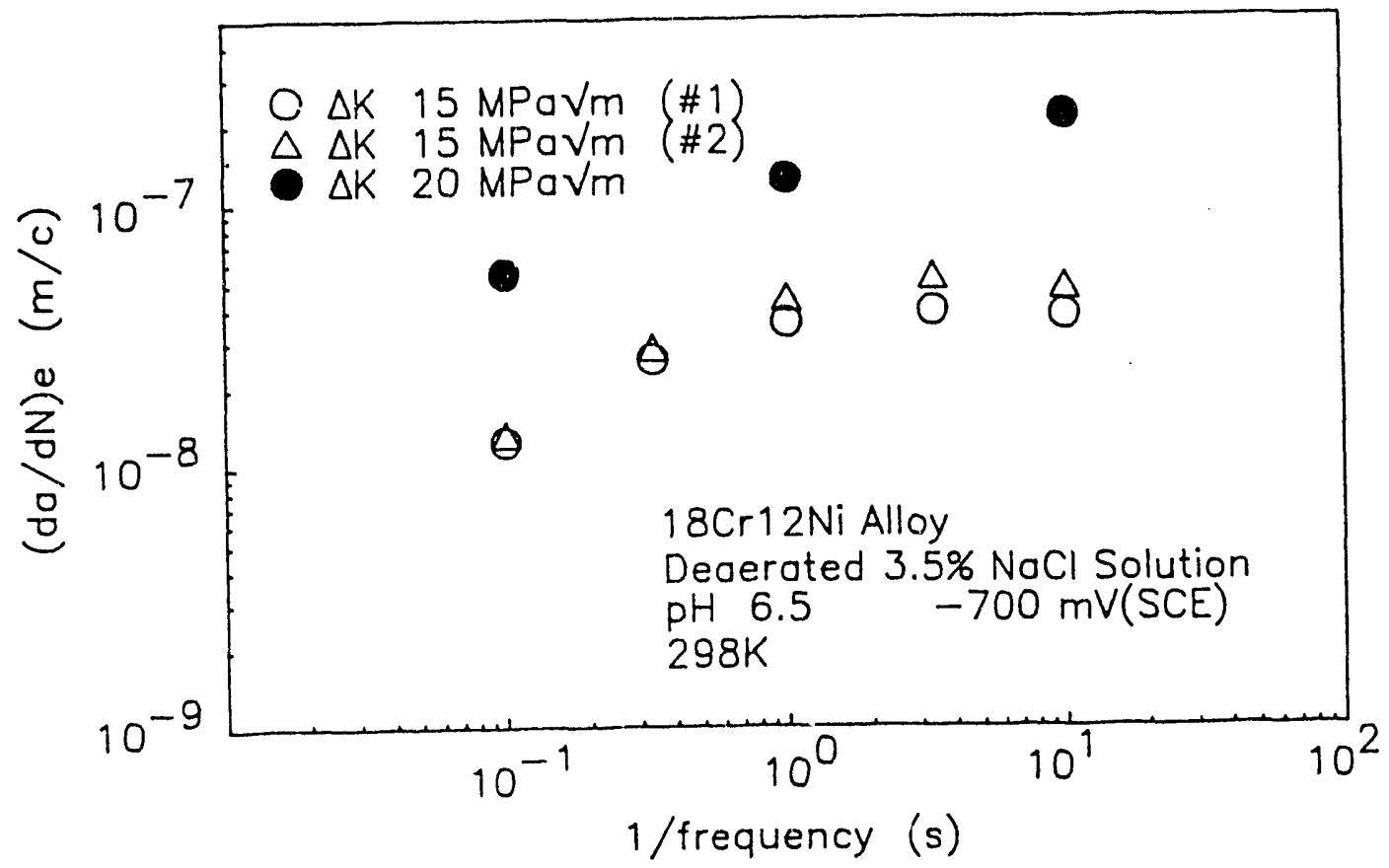

Fig. 10: Corrosion fatigue crack growth response of Fe18Cr12Ni alloy in deaerated $0.6 \mathrm{~N} \mathrm{NaCl}$ solution ( $\mathrm{pH} 6.5$ ) at room temperature and an externally applied potential of $-700 \mathrm{mV}$ SCE.

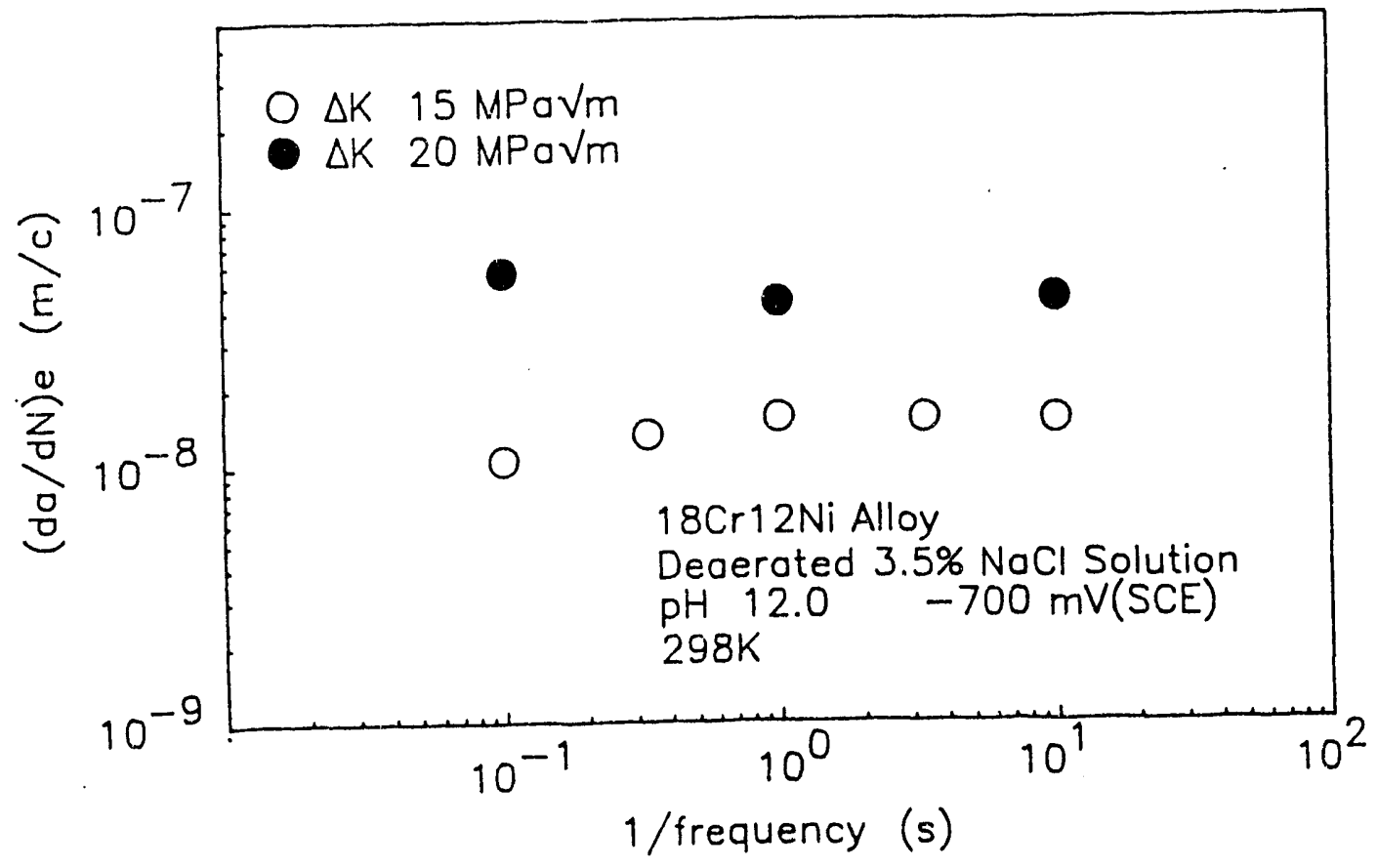

Fig. 11: Corrosion fatigue crack growth response of Fel8Cr12Ni alloy in deaerated $0.6 \mathrm{~N} \mathrm{NaCl}$ solution ( $\mathrm{pH} 12.0$ ) at room temperature and an externally applied potential of $-700 \mathrm{mV}$ SCE. 
Because the fatigue crack growth rates in vacuum are about one order of magnitude lower than those in the sodium chloride solution, these rates may be compared directly with the charge transfer data (see Figs 3 to 6). The crack growth data at the lower $\mathrm{pH}$ values conformed to the charge transfer data at the lower applied potentials ( -400 and $-480 \mathrm{mV} \mathrm{SCE})$, rather than the applied potential of $: 700 \mathrm{mV}$ SCE for the fatigue crack growth tests. The data at $\mathrm{pH}$ 12.0 correlated well with the charge transfer data at $-700 \mathrm{mV}$ SCE (as well as $-480 \mathrm{mV} \mathrm{SCE}$ ). These correlations are consistent with the previous observation that showed the crack-tip pc ential tended to remain close to the free corrosion potential [8]. The difference in the amount of charge transferred was not sufficient to account for the observed difference in crack growth rates between $\mathrm{pH} 12.0$ and the other $\mathrm{pH}$ values. The lower growth rates at. $\mathrm{pH} 12.0$ was caused, more likely, by the effect of surface film induced crack closure at the higher $\mathrm{pH}$ levels. This work is being continued, and the results will form the basis of a M.S. thesis for Mr. S. F. Chen. Additional work is also in progress to study the influence of temperature on corrosion fatigue crack grov'th.

There was indication of chemically-short-crack effect at each of the pH levels, whereby the corrosion fatigue crack growth rate at crack lengths less than $3 \mathrm{~mm}$ was 2 to 3 times faster than that observed at the iunger crack lengths. These data are being reanalyzed, and further crack growth and fractographic studies are planned to more fully examine this phenomenon.

\section{Fractographic Analysis of Corrosion Fatigue Cracks in Fe18Cr12Ni Alloy}

Preliminary fractographic examinations have been conducted on corrosion fatigue cracks in the annealed $\mathrm{Fe} 18 \mathrm{Cr} 12 \mathrm{Ni}$ alloy that had been tested in deaerated $0.6 \mathrm{~N}(3.58) \mathrm{NaCl}$ solution ( $\mathrm{pH}=2$ to 12 ) at room temperature. Examination of specimens tested in air was also made for comparison. The results are considered in relation to the crack growth response and are compared against those for annealed (DoE pedigree) and cold-rolled 304 stainless steels [9].

The morphology of fracture surfaces produced by corrosion fatigue crack growth in $0.6 \mathrm{~N} \mathrm{NaCl}$ solution (at $\mathrm{pH}-2$ to 12 ) and in air was similar, and is shown by the typical microfractographs in Fig. 12. Crack growth occurred predominantly by quasi-cleavage (see Fig. 13). Cracking along austenite grain boundaries and twin boundaries was very much in evidence (see Figs 12, 14 and 15). The austenite boundaries appeared to be clean, and thus essentially free of carbide phases (Fig. 14), while some of the twin boundaries showed evidence of phase transformation adjacent to the boundaries. The amount of boundary cracking appeared to be greater than that observed in the Fe18Cr8Ni alloys [9], and showed slight increase with decreasing loading frequency. Grain boundary separation also appeared to be less at $\mathrm{pH} 12$, but was nearly the same at the other $\mathrm{pH}$ levels. Figure 16 shows a localized region in which the crack path changed among the three modes. The abrupt changes in local crack direction suggested the sensitivity of certain grain boundary orientation and structure to cracking, which requires further investigation. The observed crack paths are consistent with those of the Fel8Cr8Ni alloys, where cracking tended to follow (001) quasi-cleavage planes, and favorably oriented (111) twin and austenite grain boundaries.

To better understand the micromechanisms for crack growth and the influence of microstructure, $0.2 \mathrm{~mm}$ thick specimens of the Fe18Cr12Ni alloy were 


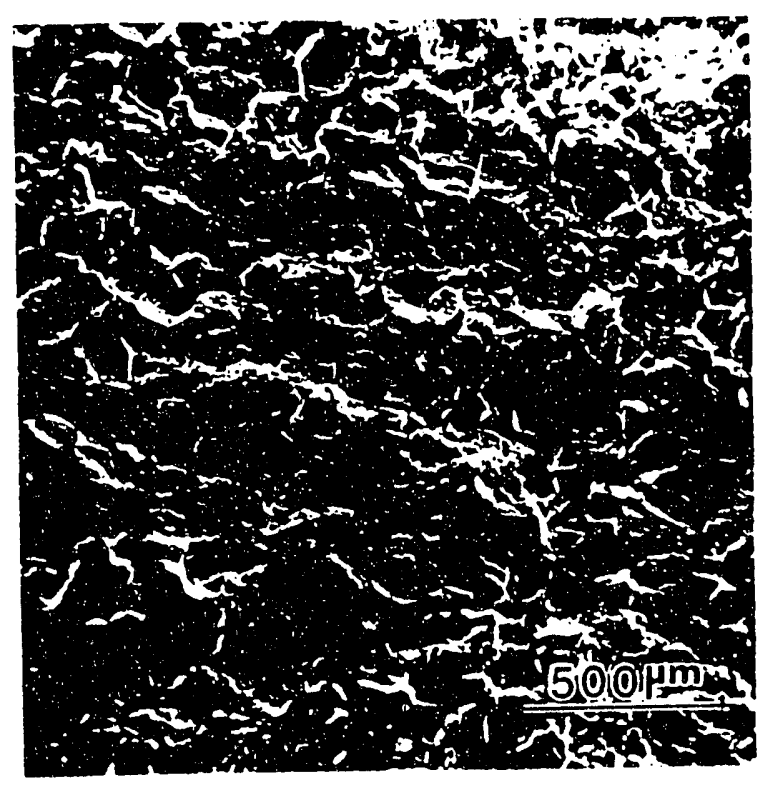

Fig. 12: Typical SEM microfractograph of a corrosion fatigue fracture surface in a Fe18Cr12Ni alloy, tested in deaerated $0.6 \mathrm{~N} \mathrm{NaCl}$ solution $(\mathrm{pH} 6.5)$ at $\Delta \mathrm{K}=15 \mathrm{MPa} / \mathrm{m}$, showing evidence of substantial austenite grain boundary and twin boundary cracking dispersed amongst the predominantly transgranular cracking mode.

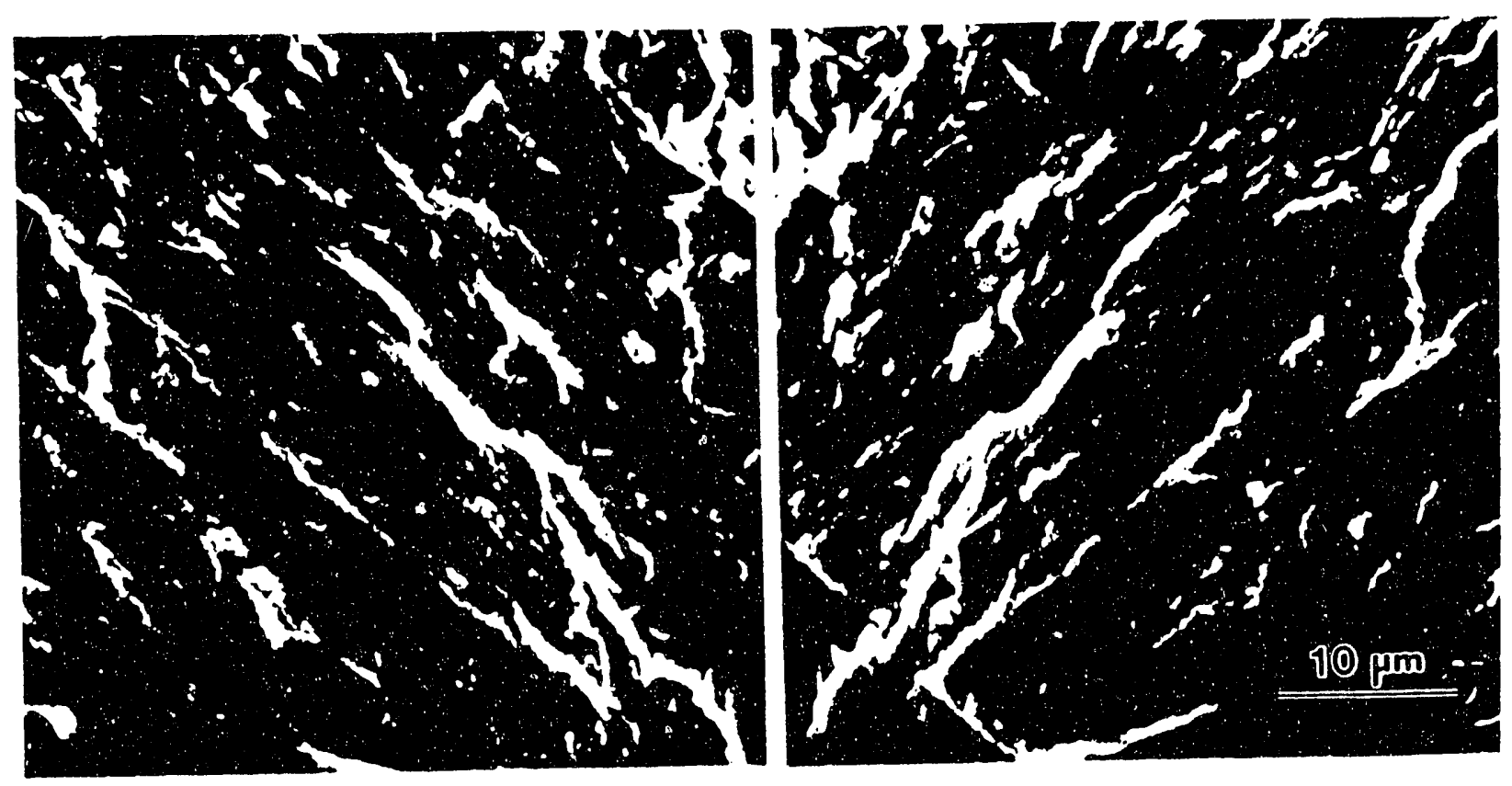

Fig. 13: SEM microfractograph of matching corrosion fatigue fracture surfaces in a Fe18Cr12Ni alloy, tested in deaerated $0.6 \mathrm{~N} \mathrm{NaCl}$ solution $(\mathrm{pH} 6.5$ ) at $\Delta \mathrm{K}=15 \mathrm{MPa} / \mathrm{m}$, showing the predominantly transgranular quasi-cleavage cracking mode. 

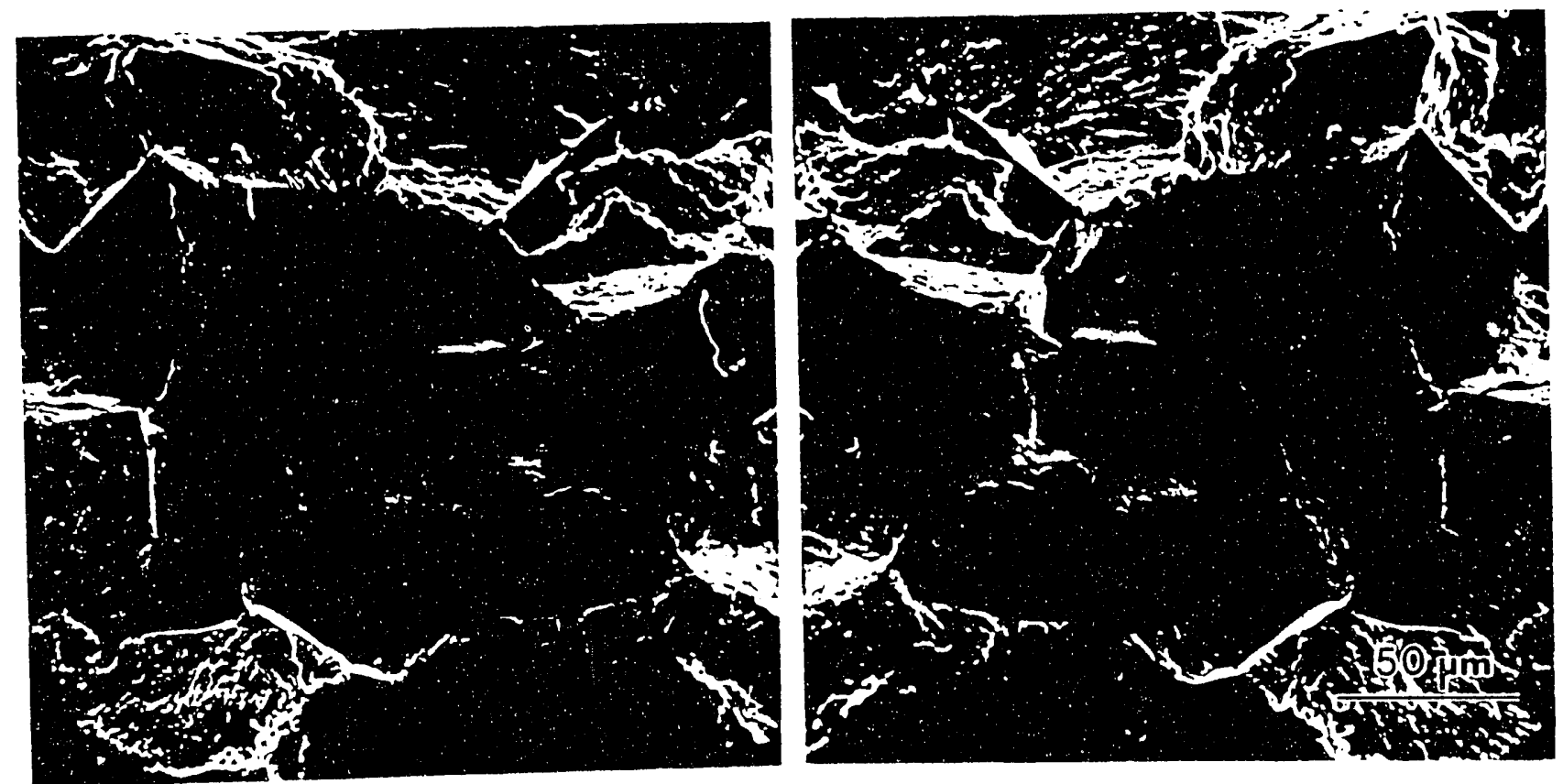

Fig. 14: SEM microfractograph of matching corrosion fatigue frac. ture surfaces in a Fel $8 \mathrm{Cr} 12 \mathrm{Ni}$ alloy, tested in deaerated $0.6 \mathrm{~N} \mathrm{NaCl}$ solution $(\mathrm{pH} 6.5)$ at $\Delta \mathrm{K}=15 \mathrm{MPa} / \mathrm{m}$, showing intergranular separation along austenite grain boundaries.
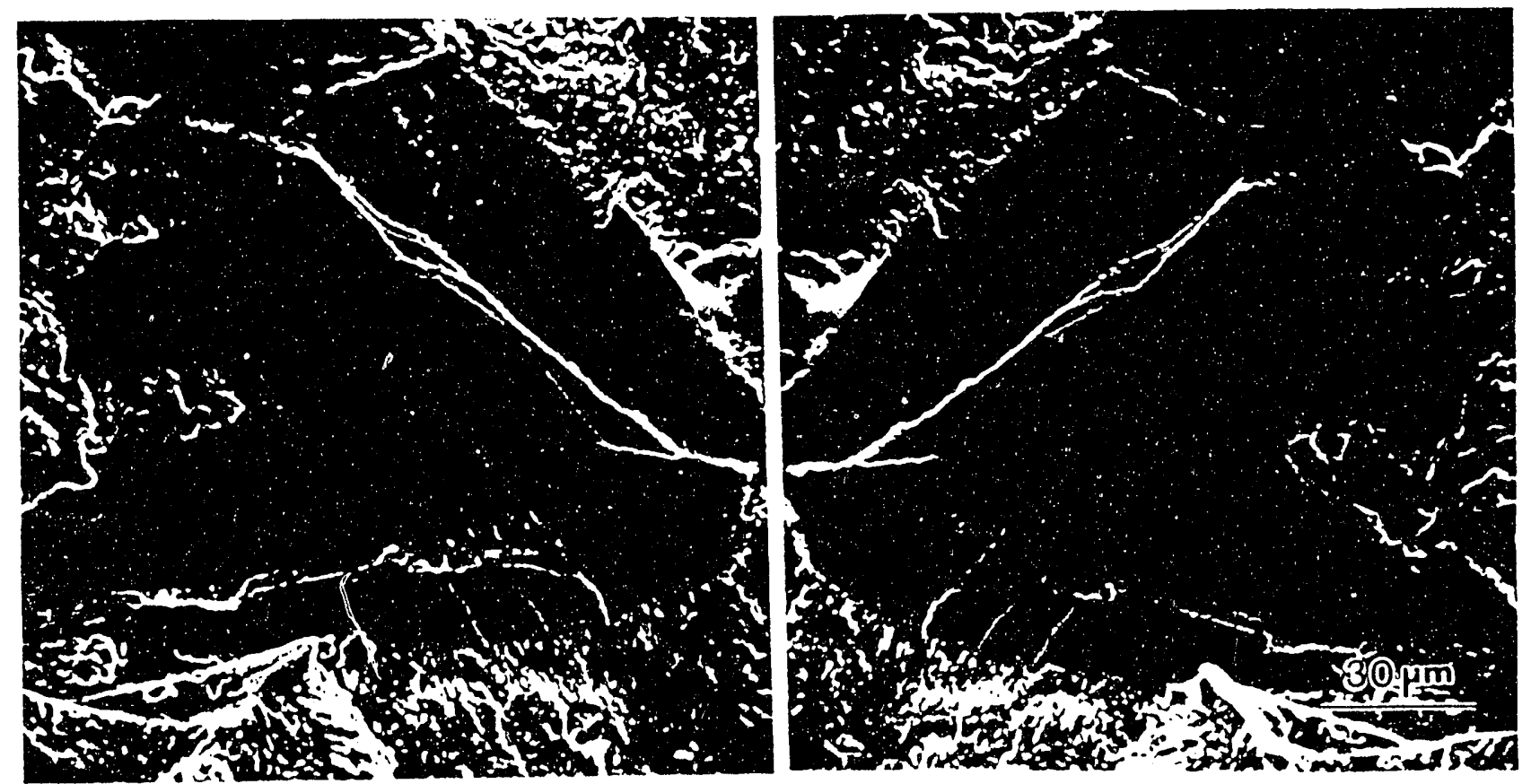

Fig. 15: SEM microfractograph of matching corrosion fatigue frac ture surfaces in a Fel8Cr12Ni alloy, tested in deaerated $0.6 \mathrm{~N} \mathrm{NaCl}$ solution (pH 6.5) at $\Delta K=15 \mathrm{MPa} / \mathrm{m}$, showing spparation along twin boundaries. 

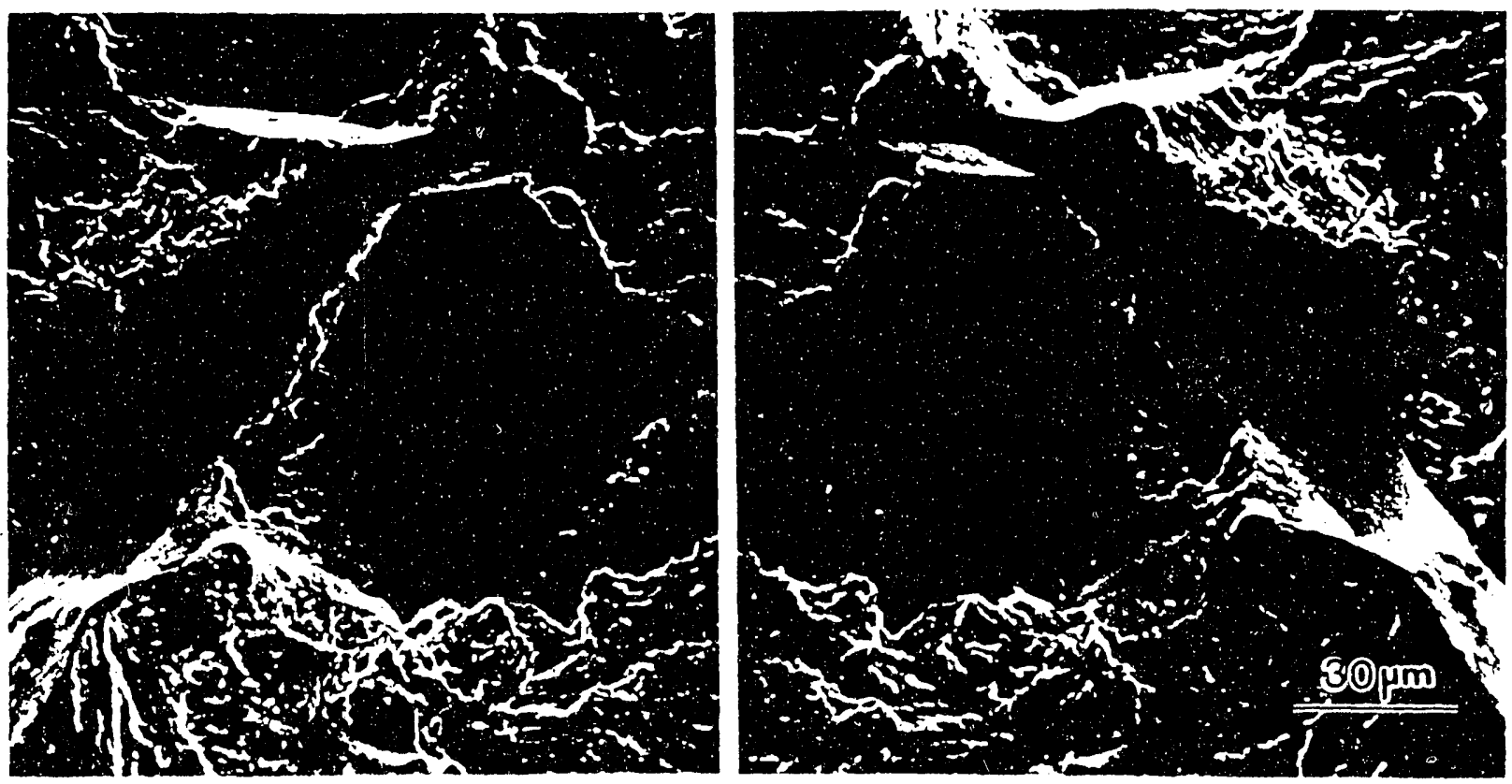

Fig. 16: SEM microfractograph of matching corrosion fatigue fracture surfaces in a Fe $18 \mathrm{Cr} 12 \mathrm{Ni}$ alloy, tested in deaerated $0.6 \mathrm{~N} \mathrm{NaCl}$ solution (pll 6.5) at $\Delta K=15 \mathrm{MPa} / \mathrm{m}$, showing changes in fracture path in neighboring austenite grains.

cathodically charged with hydrogen in a $1 \mathrm{~N} H, \mathrm{SO}$, solution, containing $0.25 \mathrm{~g} / \mathrm{L}$ of $\mathrm{Na}_{2} \mathrm{AsO}_{2}$ as a hydrogen recombination poison. "Charging was carried out at a current density of $100 \mathrm{~mA} / \mathrm{cm}^{2}$ for 15 and 60 minutes. These conditions are quite severe. If all of the hydrogen entered the specimens, 5he estinatgd average hydrogen concentration would be about 0.3 and $1.2 \times 10^{23}$ atoms/cm , respectively.

Scanning electron micrographs showing the surfaces of charged specimens are shown in Figs 17 and 18. Figure 17 show extensive cracking of the austenite grain boundaries and cwin boundaries, following 60 minutes of charging. There was considerable cracking, within the austenite grains, many of which appeared to occur along preferred parallel planes. The rumpled appearance of many of the grains suggest that martensitic transformation had taken place; some of the cracking may have taken place through specific planes of the martensite or along the martensite boundaries. Charging at the shorter time induced the same cracking features (albeit to a much smaller degree), and suggest certain of the boundaries might be more susceptible than others to hydrogen embrittlement.

It is informative to compare the cracking tendency of the charged specimens (Figs 17 and 18) against the morphology of the surfaces produced by corrosion fatigue (Figs 13 to 16). There is a clear parallel between each of the fracture features (i.e., identity in cracking mechanisms), and indication of why the crack path would change from grain to grain. The extent of microstructural damage as indicated by the microfractographs, relative to the hydrogen charged specimens, suggests that the hydrogen concentration at the crack tip would be high. A very rough estimate suggesis that concentration of 


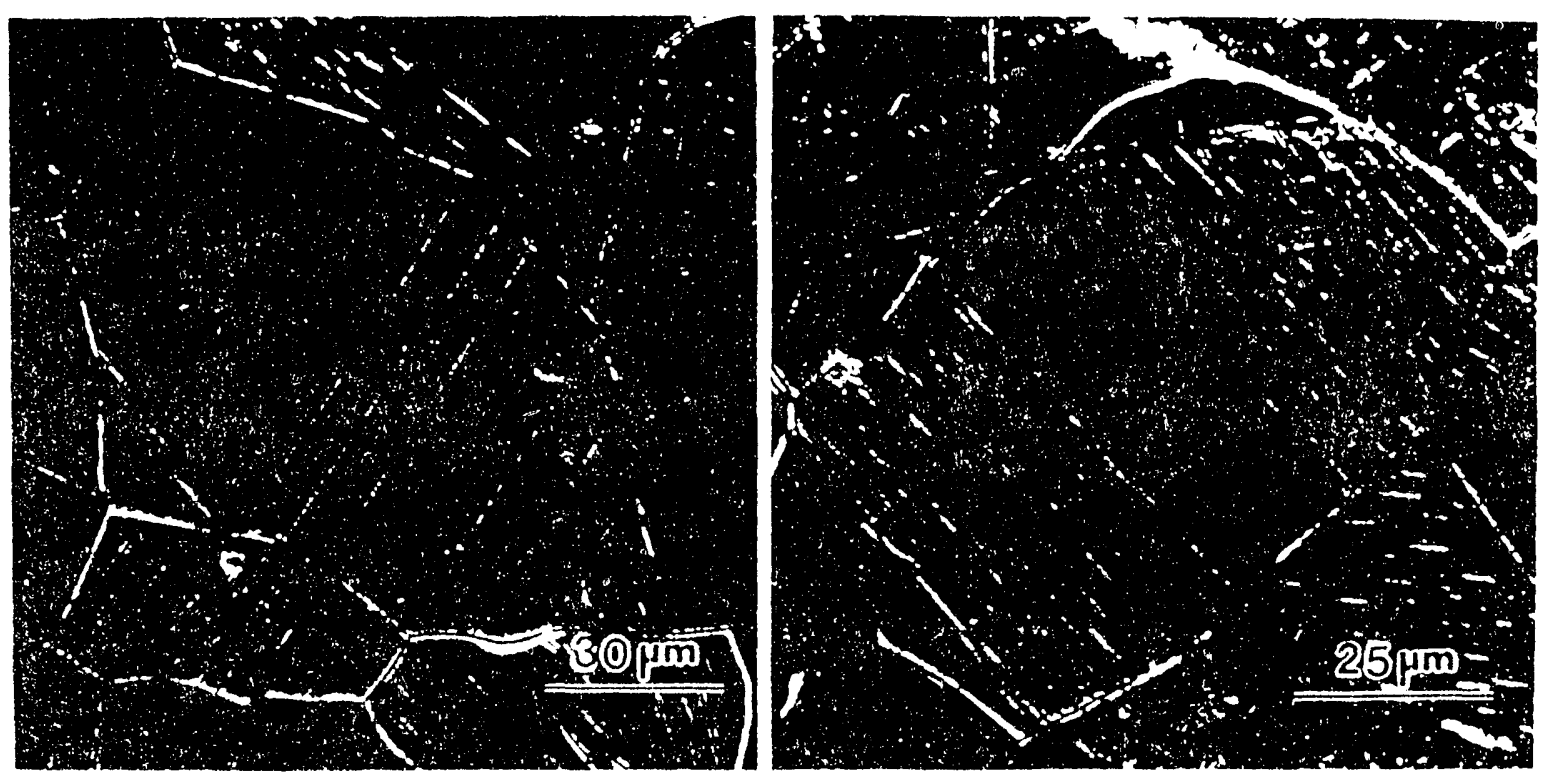

Fig. 1?: SEM mirrographe of surfaces of annealed felecrlani allog that had been, chatged with hodrogen in a lit $\mathrm{H}_{2} \mathrm{SO}, \mathrm{Na}, \mathrm{AsO}$, solution at 100 misme tor on minutes, showing extensive crackitig, of aus tentie grain and twin bendaries, erackinp, along preferred planes within the pains and evidence col matensitic tansformation.
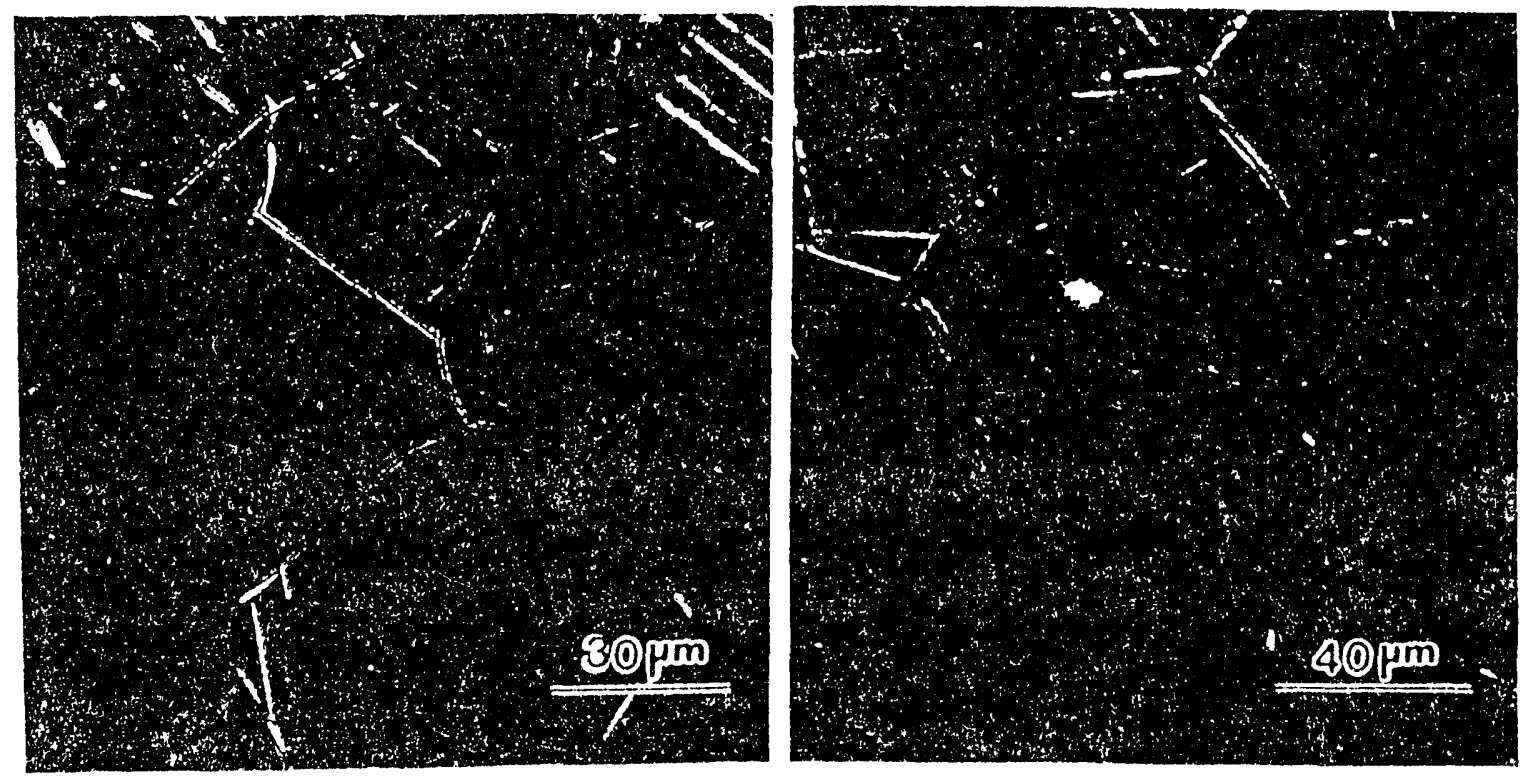

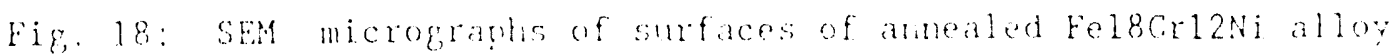
that had been charged with hydrogen in a lat 11,50 , tha, Aso, solution

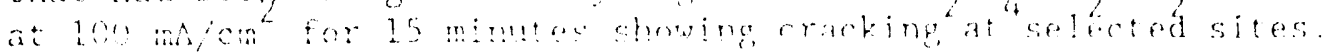


the order $10^{22}$ hydrogen $/ \mathrm{cm}^{3}$ might be attained, if all of the hydrogen produced by one to two monolayers of reactions with the newly created crack surfaces is confined to a region at the crack tip that is equal to the crack growth increment per loading cycle.

The strong correlation between the crack paths for corrosion fatigue and the cracking pattern in hydrogen charged specimens, taken together with the crack growth and electrochemical data, provide support for a hydrogen embrittlement mechanism for corrosion fatigue crack growth in these austenitic stainless steels. The correlation suggests that hydrogen charging would be a useful auxiliary tool for studying the micromechanisms for cracking; including hydrogen embrittlement of the transformed $\alpha^{\prime}$-martensite. Further studies, combining scanning and transmission electron microscopy, and electron channeling, are being continued, and are also included in the proposed continuation of research.

\section{Preparation of Bicrystals on the Fe18Cr12Ni Alloy}

To examine the influence of grain boundary orientation and structure on hydrogen concentration in the boundaries and on their fatigue properties, a limited number of experiments were planned for Fe18Cr12Ni bicrystals. These bicrystals are not available commercially and need to be produced. Attempts were made during this period to prepare bicrystals of Fe18Cr12Ni alloy by a "strain-annealing technique". This work is intended to serve the following two purposes. Firstly, the preparation of small bicrystals that can be used for characterization of grain boundary orientation and structure and for preliminary studies of grain boundary effects. Secondly, the preparation of small single crystals that can be used as seeds for growing bicrystals by using a "floating zone electron beam melting technique" (with the modified match-up seed method).

The strain-annealing technique consists of the following steps: (1) cold rolling of $12.5-\mathrm{mm}$-diameter rods of $\mathrm{Fe} 18 \mathrm{Cr} 12 \mathrm{Ni}$ alloy into 2.5 -mm-thick strips and machining into specimens with a 10 -mm-wide reduced-section for straining; (2) stress relieving at $475^{\circ} \mathrm{C}$ for $24 \mathrm{~h}$ and then annealing in vacuum $\left(<1 \times 10^{\circ}\right.$ torr) at $1050^{\circ} \mathrm{C}$ for $12 \mathrm{~h}$; (3) electrolytically polishing both surfaces of each specimen; (4) deforming each specimen in tension to a strain level of 2 to 38 ; (5) re-annealing in vacuum at $1200^{\circ} \mathrm{C}$ for $2 \mathrm{~h}$; and (6) repeating steps (4) and (5) until the grain diameters become $10 \mathrm{~mm}$ or larger. At grain diameters of $10 \mathrm{~mm}$ or larger, it is expected that the specimens $(2 \times 10 \times 20 \mathrm{~mm})$ would contain only two grains in the reduced section.

Although grain diameters of up to $8 \mathrm{~mm}$ have been obtained, the technique proved to be time consuming and ineffective in producing bicrystals with control. The procedure has been modified to permit active straining during the annealing treatment. Further experimental work, using this modified procedure, is in progress and will be continued. Alternatives for studying the role of boundaries are also being examined, and are included in the proposed continuation of research. One is to study large grained (1 to $2 \mathrm{~mm}$ diameter) material, using electron channeling and other analytical microscopy techniques to characterize grain boundary orientation and structure. The other is to have bicrystals produced by cooperating laboratories using a modified Bridgman technique. Discussions have been initiated with Sandia Livermore and with HOWMET Corporation. 


\section{REFERENCES}

1. R. P. Wei and A. Alavi, Scripta Metall., 22, 969 (1987).

2. R. P. Wei, M. Gao and P. Y. Xu, J. Electrochem. Soc., 136, 1835 (1989).

3. G. T. Burstein and D. H. Davies, J. Electrochem. Soc., 128, 33 (1981).

4. G. T. Burstein and R. C. Newman, J. Electrochem. Soc., 128, 2270 (1981).

5. R. C. Newman and K. Sieradzki, Corros. Sci., 23, 363 (1983).

6. R. G. Kelly and R. C. Newman, J. Electrochem. Soc., 137, 357 (1990).

7. R. P. Wei and $M$. Gao, "Further Observations on the Validity of Bare Surfare Current Densities Determined by the Scratched Electrode Technique", submitted to J. Electrochem. Soc. (1990).

8. R. P. Wei, in Advances in Fracture Research, Proceedings of Seventh International Conference on Fracture, Houston, TX, March, 1989, K. Salama, K. Ravi-Chandar, D.M.R. Taplin and P. Rama Rao, eds., Permagon Press, Oxford, England, 1989, pp. 1525-1544.

9. Ming Gao, Shuchun Chen and Robert P. Wei, "Crack Paths, Microstructure, and Fatigue Crack Growth in Annealed and Cold-Rolled AISI 304 Stainless Steels", accepted for publication in Met. Trans. A (1990).

Presentations and Publications (cumulative; DoE/BES related items are denoted by an asterisk)

"The Kinetics Aspects of Hydrogen Embrittlement", R. P. Wei, 2nd National Aero-space Plane (NASP) Workshop: Hydrogen-Materials Interactions, Scottsdale, AZ, June 2, 1988.

* Bare Surface Reactions and Crack Growth in Steels: A New Perspective", R. P. Wei, Gordon Research Conference on Corrosion, New London, NH, July 21, 1988 .

"Deformation and Subcritical Crack Growth Under Static Loading", HuI Yin, Ming Gao and R. P. Wei, 1988 TMS Fall Meeting, Chicago, IL, September 27, 1988 .

"Stress Corrosion Cracking of High-Strength Steels in Aqueous Environments", H. C. Chu, Ming Gao and R. P. Wei, 1988 TMS Fall Meeting, Chicago, IL, September 28, 1988 .

*"Chemically-Induced Crack Length Effects in Corrosion Fatigue of AISI 304 Stainless Steel", D. E. Allison, A. Alavi, M. Gao and R. P. Wei, 1988 TMS Fall Meeting, Chicago, IL, September 28, 1988.

*"In Situ Fracture Techniques for Studying Transient Reactions With Bare Steel Surfaces", R. P. WeI and A. Alavi, 174th Fall Meeting of Electrochemical Society, Chicago, IL, October 10, 1988.

"Electrochemical Considerations of Crack Growth in Ferrous Alloys, R. P. We1, Seventh International Conference on Fracture (ICF7), Houston, TX, March 20$24,1989$.

"Corrosion Fatigue Crack Growth and Reactions With Bare Steel Surfaces", R. P. Wei, CORROSION/89, New Orleans, LA, April 17-21, 1989. 
"Identification of Hydride Phases in Thermally Charged Titanium Aluminides", Ming Gao, Bart Boodey and Robert P. We1, 3rd NASP Workshop: Hydrogen-Materials Interactions, Scottsdale, AZ, May 31-June 2, 1989.

"Phase Transformation and Moisture Induced Crack Growth in Yttria Stabilized Zirconia", R. P. We1, International Conference on Mechanistic Aspects of Fracture, Irsee, W. Germany, June 19-23, 1989.

*"Environmental and Microstructural Considerations of Corrosion Fatigue Crack Growth", R. P. We1, FRACTURE '89, Johannesburg, South Africa, June 29, 1989.

"Corrosion Fatigue Crack Growth and Electrochemical Reactions for A X-70 Linepipe Steel in Carbonate-Bicarbonate Solution, R. P. We1, FRACTURE '89, Johannesburg, South Africa, June 29, 1989.

* Hydrogen Embrittlement and Environmentally Assisted Crack Growth", R. P. We1, Fourth International Conference on The Effects of Hydrogen on Material Behavior, Jackson Lake Lodge, WY, September 14, 1989.

* "Bare Surface Reactions and Mechanisms for Corrosion Fatigue Crack Growth", R. P. We1, DOE/BES/DMS Contractors' Meeting, Oakland, CA, September 21, 1989.

"Environmentally Assisted Fatigue Crack Growth in an Alumina Reinforced Aluminum Alloy", R. P. Wei, ALCAN Meeting, Chicago, IL, September 28, 1989.

"Identification of New Precipitates in Peak Aged Al-Mg-Si (6061-T6) Aluminum Alloy", M. Gao and R. P. Wei, 1989 TMS Fall Meeting, Indianapolis, IN, October 2, 1989.

* "Crack Paths and Corrosion Fatigue Crack Growth in 304 Stainless Steels", Ming Gao, Shuchun Chen and R. P. Wei, 1989 TMS Fall Meeting, Indianapolis, IN, October 2, 1989.

"Environmentally Assisted Crack Growth and Predictions of Service Life", R. $P$. We $i$, ONR Workshop on Life Predictions, National Institute of Standards and Technology, Gaithersburg, MD, October 27, 1989.

"Mechanistic Considerations of Corrosion Fatigue of Steels", R. P. We1, International Conference on Evaluation of Materials Performance in Severe Environments (EVALMAT 89), November 20, 1989.

*"Bare Surface Reactions and Mechanicsms for Corrosion Fatigue Crack Growth in Steels", R. P. Wei, Nippon Steel Corporation, R\&D Liboratories II, Sagamihara, Japan, November 24, 1989.

* "Rate Controlling Processes and Ccrrosion Fatigue Crack Growth", Robert P. We1, Materials Science Colloquia, University of Virginia, Charlottesville, VA, April 2, 1990.

"Phase Transformation and Sustained-load Crack Growth in Yttria Stabilized Zirconia", Hui Yin and R. P. Wel, American Ceramic Soclety, Dallas, TX, April $24,1990$. 
*"Bare Surface Reactions and SCC and CF Crack Growth in Ferrous Alloys: A New Approach to Understanding", R. P. We1, Seminar at the University of Erlangen, Erlangen, Germany, July 27, 1990.

* "Scratching Electrode Technique -. What is Being Measured", Ming Gao, DOE/BES Contractors' Meeting, Minneapolis, MN, September 13, 1990.

* "Bare Surface Reactions and SCC and CF Crack Growth in Ferrous Alloys: A New Approach to Understanding", R. P. We1, Keynote lecture for the 1990 Annual Meeting of the Chinese Society of Corrosion Engineering, Sun-Moon Lake, Taiwan, ROC, September 13, 1990.

"Phase Transformation and Sustained-load Crack Growth in Yttria Stabilized Zirconia", R. P. WeI, Industrial Technology Research Institute, Materials Research Laboratories, Taiwan, ROC, September 14, 1990.

"Environmentally Assisted Crack Growth in Ceramic Particle Reinforced Metal Matrix Composites", R. P. We1, Alcan Meeting, Kingston, Ontario, Canada, September 26, 1990.

"Misfit Strains and Mechanism for the Precipitation of Hydrides in Thermally Charged Alpha-2 Titanium Aluminides", Ming Gao, J. Bart Boodey and Robert P. Wei, TMS/ASM Fall Meeting, Detroit, MI, October 8, 1990.

Ming Gao, P. S. Pao and R. P. Wei, "Chemical and Metallurgical Aspects of Environmentally Assisted Fatigue Crack Growth in 7075-T651 Aluminum Alloy", Met. Trans. A, 19A, 1988, p. 1739.

*R. P. Wei and A. Alavi, "A 4-Electrode Analogue for Estimating Electrochemical Reactions with Bare Metal Surfaces at the Crack Tip", Scripta Met., 22, 1988, pp. $969-974$.

Robert P. Wei, "Corrosion Fatigue: Science and Engineering", Japan Society of Mechanical Engineers, 91, No. 841, December 1988, pp. 8-13 (in Japanese).

Robert P. Wei and Richard P. Gangloff, "Environmentally Assisted Crack Growth in Structural Alloys: Perspectives and New Directions", in Fracture Mechanics: Perspectives and Directions (Twentieth Symposium), ASTM 1020, Robert P. Wei and Richard P. Gangloff, eds., Soc. of Testing \& Mat1s., Philadelphia, PA, 1989, pp. 233-264.

R. P. Wei, "Chemical and Microstructural Aspects of Corrosion Fatigue Crack Growth" in Fracture Mechanics: Microstructure and Micromechanisms, Proceedings of ASM 1987 Materials Science Seminar, S. V. Nair, J. K. Tien, R. C. Bates and O. Buck, eds., ASM International, Metals Park, Ohio, 1989, pp. 229-254.

*Y. Nakai and R. P. Wei, "Measurement of Short Crack Lengths by an AC Potential Method", Eng'g. Fract. Mech., 32(4), 1989, pp. 581-589.

R. P. Wei, "Environmentally Assisted Fatigue Crack Growth", in Advances in Fatigue Science and Technology, Moura Branco and L. Guerra Rosa, eds., Kluwer Academic Publishers, 1989, pp. 221-252. 
R. P. Wei, "Electrochemical Considerations of Crack Growth in Ferrous Alloys", Advances in Fracture Research, Proceedings of Seventh International Conference on Fracture, Houston, TX, March, 1989, K. Salama, K. Ravi-Chandar, D.M.R. Taplin and P. Rama Rao, eds., Permagon Press, Oxfor:, England, 1989, pp. 1525-1544.

*R. P. Wei and A. Alavi, "In Situ Fracture Techniques for Studying Transient Reactions with Bare Steel Surfaces", Proceedings of 174 th Fall Meeting of Electrochemical Society on Transient Techniques in Corrosion, Chicago, IL, October, 1988, Electrochemical Society, 1989 (also submitted for publication in J. Electrochem. Soc.).

*R. P. Wei, M. Gao and P. Y. Xu, "Peak Bare-Surfane Densities Overestimated in Straining and Scratching Electrode Experiments", J. Electrochem. Soc., 136, No. 6, June 1989, pp. 1835-1836.

R. P. Wei, "Corrosion Fatigue Crack Growth and Reactions With Bare Steel Surfaces", Paper 569, Proceedings of Corrosion 89, New Orleans, LA, April $17-$ 21,1989 , to be published.

H. Yin, M. Gao and R. P. Wei, "Deformation and Subcritical Crack Growth under Static Loading", J. Matls. Sci. \& Engr., A119, 1989, pp. 51-58.

Ming Gao, J. Bart Boodey and Robert P. Wei, "Identification of Hydride Phases in Thermally Charged Titanium Aluminides", Proceedings of 3rd NASP Workshop Hydrogen-Materials Interactions, May 31-June 2, 1989, Scottsdale, AR, to be published.

*Yoshiyuki Kondo and Robert P. Wei, "Approach On Quantitative Evaluation of Corrosion Fatigue Crack Initiation Condition", Proceedings of International Conference on Evaluation of Materials Performance in Severe Environments, EVALMAT 89, Kobe, Japan, November 20-23, 1989, accepted for publication.

Robert P. Wei, "Mechanistic Considerations of Corrosion Fatigue of Steels", Proceedings of International Conference on Evaluation of Materials Performance in Severe Environments, EVALMAT 89, Kobe, Japan, November 20-23, 1989, accepted for publication.

H. C. Chu and R. P. Wei, "Stress Corrosion Cracking of High-Strength Steels in Aqueous Environments", CORROSION, 46, No. 6, June 1990, pp. 468-476.

R. P. Wei and M. Gao, "Hydrogen Embrittlement and Environmentally Assisted Crack Growth", in Hydrogen Effects on Material Behavior, Neville R. Moody and Anthony W. Thompson, Eds., The Minerals, Metals \& Materials Society, 1990, pp. $789-816$.

Ming Gao, J. Bart Boodey and Robert P. Wei, "Hydrides in Thermally Charged Alpha-2 Titanium Aluminides", Scripta Met. et Matl., 24, 1990, pp. 2135-2138.

*Ming Gao, Shuchun Chen and Robert P. Wei, "Crack Paths, Microstructure, and Fatigue Crack Growth in Annealed and Cold-Rolled AISI 304 Stainless Steels", accepted for publication in Met. Trans. A (1990). 
Ming Gao, J. Bart Boodey, and Robert P. Wei, "Misfit Strains and Mechanism for the Precipitation of Hydrides in Thermally Charged Alpha-2 Titanium Aluminides", Proceedings of TMS/ASM Fall Meeting, Detroit, MI, October, 1990, to be published.

James P. Thomas and Robert P. Wei, "Corrosion Fatigue Crack Growth of Steels in Aqueous Solutions - I. Experimental Results \& Modeling The Effects of Frequency and Temperature", submitted to Matls. Sci. \& Engr.

James P. Thomas and Robert P. Wei, "Corrosion Fatigue Crack Growth of Steels in Aqueous Solutions - II. Modeling The Effects of Delta K", submitted to Matls. Sci. \& Engr.

*R. P. Wei and M. Gao, "Further Observations on the Validity of Bare Surface Current Densities Determined by the Scratched Electrode Technique", submitted to J. Electrochem. Soc.

*R. P. Wei and M. Gao, "Distribution of Initial Current Between Bare and Filmed Surfaces (What is Being Measured in a Scratched Electrode Test?)", submitted as an Accelerated Brief Communication to J. of Electrochem. Soc.

\section{Personne1}

During the past 12 months, the following personnel were associated with this grant in addition to $\mathrm{Dr}$. Robert $\mathrm{P}$. Wei, Principal Investigator: $\mathrm{Dr}$. Ming Gao and Messrs. Shuchun Chen and Shyuan-Fang Chen. Dr. Gao is a Senior Research Scientist fium the People's Republic of China and is participating in the program on a part-time basis. He is responsible for the mechanical and microstructural aspects of the program. He assists Dr. Wei in addressing the problems of corrosion fatigue mechanisms and modeling of corrosion fatigue crack growth. Mr. S. C. Chen is a Ph.D. candidate in Materials Science and Engineering, and is studying the microstructural aspects of corrosion fatigue crack growth. Mr. S. F. Chen is a M.S. candidate in Applied Mechanics in the Department of Mechanical Engineering and Mechanics, is studying corrosion fatigue crack growth response in relation to electrochemical reactions with bare surfaces.

\section{Awards and Honors}

Dr. Robert P. Wei was granted a Senior U. S. Scientist Award by the Alexander von Humboldt Foundation in December 1989 for a 12 -month period of research studies in Germany. As a part of this award, Dr. Wei is conducting cooperative research on corrosion fatigue in aqueous environments with scientists at the GKSS Forschungszentrum, a German government laboratory, located in Geesthacht (near Hamburg), and spent the past summer there, principally for planning. He will complete his tenure from January to September, 1991 at GKSS .

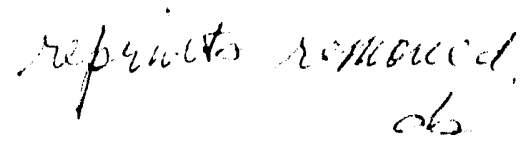



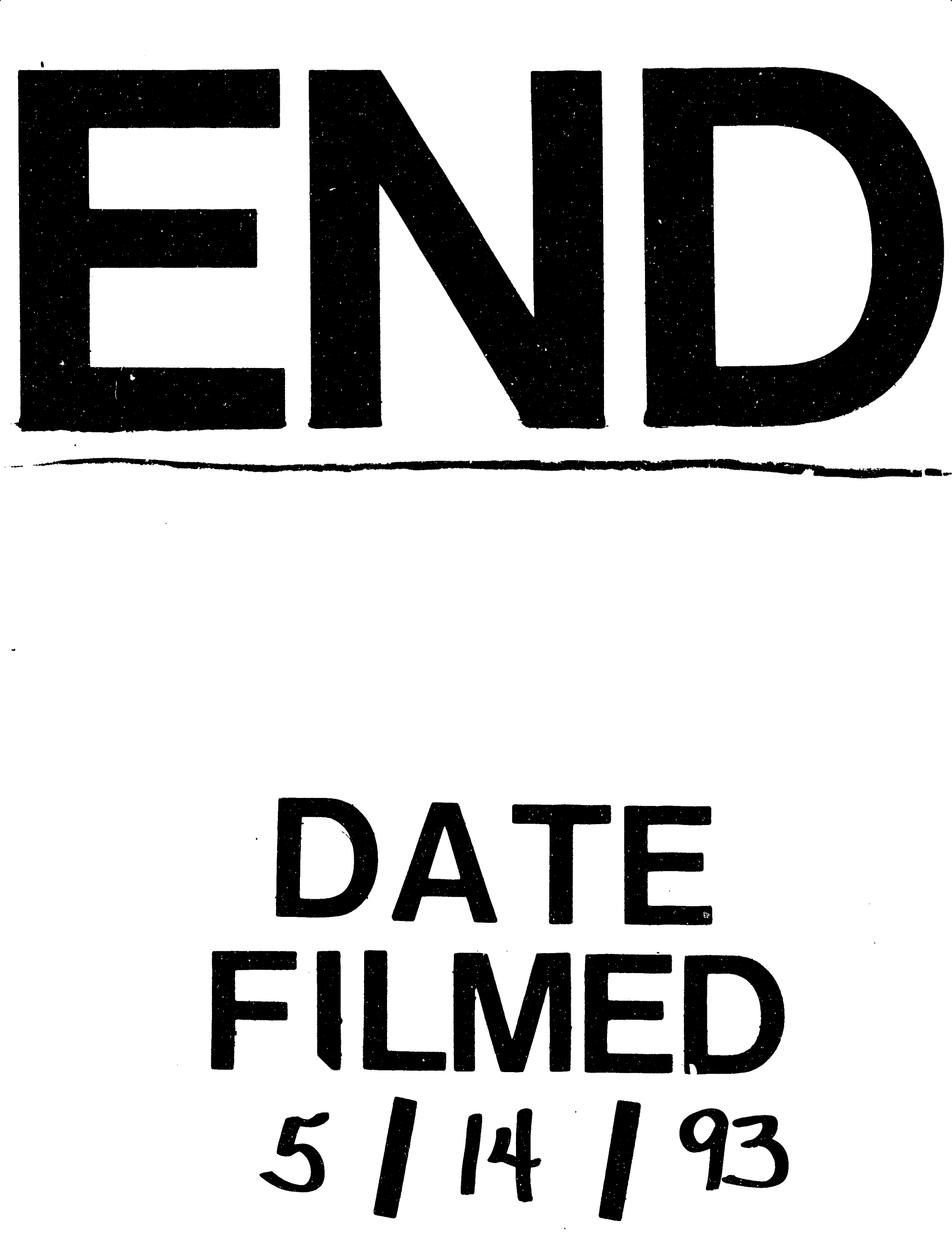
